\title{
Integration of geothermal water into secondary network by
}

\section{absorption-heat-pump-assisted district heating substations}

Zixu Song ${ }^{a, 1}$, Na Wang ${ }^{a, 1}$, Shijun You ${ }^{a, b}$, Yaran Wang ${ }^{a, b^{*}}$, Huan Zhang ${ }^{a, b}$, Shen $\mathrm{Wei}^{c}$, Xuejing Zheng ${ }^{a, b}$, Jin Guo ${ }^{a}$

${ }^{a}$ School of Environmental Science and Engineering, Tianjin University, Tianjin 30072, PR China.

${ }^{b}$ Tianjin Key Lab of Biomass/Wastes Utilization, Tianjin 300350, PR China.

${ }^{c}$ The Bartlett School of Construction and Project Management, University College London (UCL), 1 19 Torrington Place, London WC1E 7HB, United Kingdom.

*Corresponding Author: Tel. / Fax: +86 222740 0832. E-Mail address: yaran_wang@tju.edu.cn.

\section{Abstract}

Integrating renewable energy into District Heating (DH) systems can significantly save the consumption of fossil energy and receive environmental benefits. The 4 th Generation District Heating (4GDH) is the most promising technique for future DH systems by decreased supply temperature and use of low-temperature renewable thermal sources. As current district heating networks are mostly designed with supply temperature around $100^{\circ} \mathrm{C}$, high hydraulic resistance and large pressure loss may often occur if decreasing the supply temperature to $30-70^{\circ} \mathrm{C}$. This paper has proposed a Composite District Heating Substation (CDHS) with integrated geothermal water into the secondary network by Absorption Heat Pump (AHP). This has been demonstrated to be a feasible and effective solution for using low-temperature geothermal water in DH systems, without decreasing supply temperature of the primary network. The AHP is driven by hot water from the primary network, and the heat of the geothermal water could be used more intense by reducing its return temperature by the AHP and the plate

\footnotetext{
1 These authors contributed equally to this work.
} 
heat exchanger. In this study, both the AHP and the whole substation were simulated by MATLAB, and the results indicated that the heating capacity of AHP increased when increasing the temperature or the mass flow rate of geothermal water, the mass flow rate of the primary network, or when decreasing the return temperature of the secondary network. Additionally, it was found that using temperature regulation with flow changing in stages in the secondary network could receive a higher $C O P$ of the AHP and a higher ratio of geothermal energy used in the substation. A case study was carried out as well and its results showed that comparing to conventional DH substations, the CDHS could save $8.0 \%$ of the annual cost and reduce $25.6 \%$ of the pollutant emissions for a heating season.

Keywords: Geothermal water; District heating substation; Secondary network; Absorption heat pump; Operation regulation

\begin{tabular}{|c|c|c|c|}
\hline \multicolumn{4}{|c|}{ Nomenclature } \\
\hline$Q^{\prime}$ & Heating capacity, $\mathrm{kW}$ & $c$ & Condenser \\
\hline$m^{\prime}$ & Mass flow rate, $\mathrm{kg} / \mathrm{s}$ & $e$ & Evaporator \\
\hline$h$ & Enthalpy, $\mathrm{kJ} / \mathrm{kg}$ & $w s$ & Weak solution \\
\hline$t$ & Temperature, ${ }^{\circ} \mathrm{C}$ & $w f$ & Working fluid \\
\hline \multirow[t]{2}{*}{$c_{p}$} & Specific heat at constant & $p$ & Primary network \\
\hline & pressure, $\mathrm{kJ} /(\mathrm{kg} \cdot \mathrm{K})$ & $s$ & Secondary network \\
\hline$x$ & Concentration, $\%$ & $g w$ & Geothermal water \\
\hline \multirow[t]{2}{*}{$U$} & Heat transfer coefficient, & se & Solution exchanger \\
\hline & $\mathrm{kW} /\left(\mathrm{K} \cdot \mathrm{m}^{2}\right)$ & phe & Plate heat exchanger \\
\hline$A$ & Heat transfer area, $\mathrm{m}^{2}$ & $h w$ & Hot water \\
\hline COP & Coefficient of performance & $c w$ & Cold water \\
\hline
\end{tabular}




\begin{tabular}{|c|c|c|c|}
\hline$D$ & Circulation ratio & part & Part load \\
\hline$\delta$ & Mean-square error & $o$ & Outdoor \\
\hline$\Delta x$ & \multicolumn{3}{|l|}{ Concentration difference, $\%$} \\
\hline$\Delta t$ & Temperature difference, ${ }^{\circ} \mathrm{C}$ & \multicolumn{2}{|c|}{ Abbreviation } \\
\hline$\overline{Q^{\prime}}$ & Relative thermal load & $\mathrm{DH}$ & District heating \\
\hline$\overline{m^{\prime}}$ & Relative mass flow rate & 4GDH & 4th Generation District \\
\hline$Z$ & Annual cost, ¥/year & & Heating \\
\hline$C_{i}$ & Initial cost, $¥$ & CDHS & Composite district heating \\
\hline$C_{a o}$ & Annual operational cost, $¥ /$ year & & substation \\
\hline$j$ & Annual interest rate & AHP & Absorption heat pump \\
\hline$n$ & Service life of equipment, & PHE & Plate heat exchanger \\
\hline & year & $\mathrm{RHC}$ & Relative heating capacity \\
\hline Sub & exes & $\mathrm{TR}$ & Temperature regulation \\
\hline$g$ & Generator & TRFC & Temperature regulation with \\
\hline$a$ & Absorber & & flow changing in stages \\
\hline
\end{tabular}

\section{Introduction}

In the past few decades, improving the operational efficiency of building energy systems has led to much lower energy consumption. However, to achieve sustainable development, only through improving efficiency is not sufficient [1]. In recent years, using renewable energy to replace fossil fuel has captured increasing attentions, and integrating renewable energy into heating networks has become a major direction for development of efficient and green District Heating (DH).

In terms of renewable energy that can be used for heating buildings, there are many 
types, such as geothermal energy, solar energy, biomass energy and waste heat. The geothermal resources in China is around $3.06 \times 10^{18} \mathrm{kWh}$ per year, taking $7.9 \%$ of the total global geothermal reserves [2,3]. The exploitation of geothermal energy has little impact on the environment, so it has enormous potentials [4]. Many of such exploitation, however, is low-grade heat, making it difficult to be integrated into the current DH systems directly.

\subsection{Dilemma on integrating low-grade renewables into current DH systems}

For the current DH systems, the heat carrier is pressured water, with supply temperatures often around $100^{\circ} \mathrm{C}$. However, this temperature is too high for most lowgrade renewable heats. To achieve $100 \%$ renewable energy systems in the future, Lund et al. [5-7] proposed a concept called 4th Generation District Heating (4GDH). The heat carrier of $4 \mathrm{GDH}$ system is low-temperature water from $30^{\circ} \mathrm{C}$ to $70^{\circ} \mathrm{C}$. Ziemele et al. [810] have explored some pathways for transition to the 4GDH system, with Latvia as the research object. Pakere et al. [11] have stated that the transition to 4GDH would help to decrease specific heat losses by $10 \%$ level.

The 4GDH system, however, is designed for future energy systems [5]. Currently it is still very difficult to achieve it, especially for existing large-scale DH system. For example, the installed heating capacity of the DH network in Tianjin (China) is 11,113 MW by the end of 2015 [12]. For huge district heating network like this, upgrading pipelines and heat sources are very complex work [13]. Decreasing the supply temperature of the $\mathrm{DH}$ network to $30 \sim 70{ }^{\circ} \mathrm{C}$ will lead to smaller supply and return temperature difference. Higher flow rates within the current pipelines will largely increase the pressure losses, which challenges the distribution capacity of the current network, since the current network is designed for large temperature difference [14]. Hence, novel techniques are needed for integrating low-grade renewables into the 
existing large-scale DH network.

1.2 Recent studies on integration of renewables to DH network without decreasing the primary supply temperature

Using Absorption Heat Pump (AHP) to integrate renewable energy into the secondary network of DH systems has been proven as an effective method. Keil et al. [15] studied a solar-assisted local DH system in Munich, Germany. In this system, solar energy was utilized as heat source for absorption heat pump driven by municipal network. The performance and economy analysis revealed that this system could achieve high energetic efficiency. Li et al $[16,17]$ proposed a new type of DH systems based on absorption heat pumps as well. The system could recover the low-grade renewable energy by hot water absorption heat pump in the substation of DH systems. Based on this work, Wu et al. [18] proposed a prototype of $\mathrm{NH}_{3}-\mathrm{H}_{2} \mathrm{O}$ water source absorption heat pump. It could operate when the inlet temperature of the evaporator is as low as $-18^{\circ} \mathrm{C}$, extending the system's applicability in colder conditions. Zhang et al. $[19,20]$ explored the use of ground source absorption heat pump in DH systems, and proposed that this system was more energy efficient than ground source heat pump systems driven by electricity.

In the DH system with AHP, gradient utilization of heat is an effective method to improve the heating efficiency [21]. Fu et al. [22] have proposed an absorption heat exchange technology to decrease the return temperature of the primary network. By using AHP and Plate Heat Exchangers (PHE) in the substation, gradient utilization of the primary network was realized and the return temperature of the primary network could be lowered to approximately $20^{\circ} \mathrm{C}$. Zhao et al. [23] then presented a way to recover waste heat using an absorption heat exchanger located in the substation for the natural gas-steam combined cycle power plant. By this method, the exhaust temperature 
was decreased to $20^{\circ} \mathrm{C}$, with an improved heating ability by $61 \%$. Zhu et al. [24] developed a multi-sectional vertical absorption heat exchanger for DH systems for lower heat transfer loss and lower return water temperature, through recovering lowgrade waste heat.

\subsection{Novel DH substation integrating low-grade geothermal water into the DH system} assisted by AHP

Combining the ideas of integrating renewable energy into the secondary network of DH systems and gradient utilization, this study proposes a Composite District Heating Substation (CDHS), which integrates geothermal water into the secondary network assisted by the AHP. The CDHS utilizes geothermal water in gradient, with recharged geothermal water below $25^{\circ} \mathrm{C}$. The CDHS is composed of a single-effect $\mathrm{LiBr}-\mathrm{H}_{2} \mathrm{O}$ AHP and two plate heat exchangers. The AHP is driven by the hot water from the primary DH network. The geothermal water is utilized in gradient by firstly heating the secondary return water and then enters the evaporator side of the AHP for heat recovery.

In this study, mathematical models for AHP, PHE and CDHS were developed at the first. Then simulations were carried out for the substation under various operational conditions to identify the influences of factors, namely, 1) temperature of geothermal water at evaporator inlet, 2) mass flow rate of geothermal water, 3) return temperature of secondary network and 4) mass flow rate of primary network, on the heating capacity of AHP. For the whole substation, the operational curves of the primary network and geothermal water under different regulation methods were obtained, which can provide the basis for operation control. At the end, annual cost and pollutant emissions were compared between the newly proposed CDHS and a conventional DH substation. 


\section{System description}

The CDHS with integrated geothermal water into the secondary network mainly consists of one single-effect $\mathrm{LiBr}-\mathrm{H}_{2} \mathrm{O}$ absorption heat pump and two plate heat exchangers. In the substation, the AHP is driven by hot water with temperature between $110^{\circ} \mathrm{C}$ and $130^{\circ} \mathrm{C}$. The geothermal water is recharged below $25^{\circ} \mathrm{C}$ with gradient utilization by the AHP and the PHE.

A schematic drawing of the CDHS is shown in Fig. 1. In this substation, geothermal water first exchanges heat with the return water of secondary network through the PHE. The cooled geothermal water then enters the evaporator of the AHP and continues to be cooled down. The AHP is driven by hot water from the primary DH network. The return water of the secondary network is heated by the condenser and absorber of the AHP. After coming out of the generator in AHP, the primary hot water continues to exchange heat with the return water of secondary network through the PHE. The return water of secondary network has three parallel branches. 


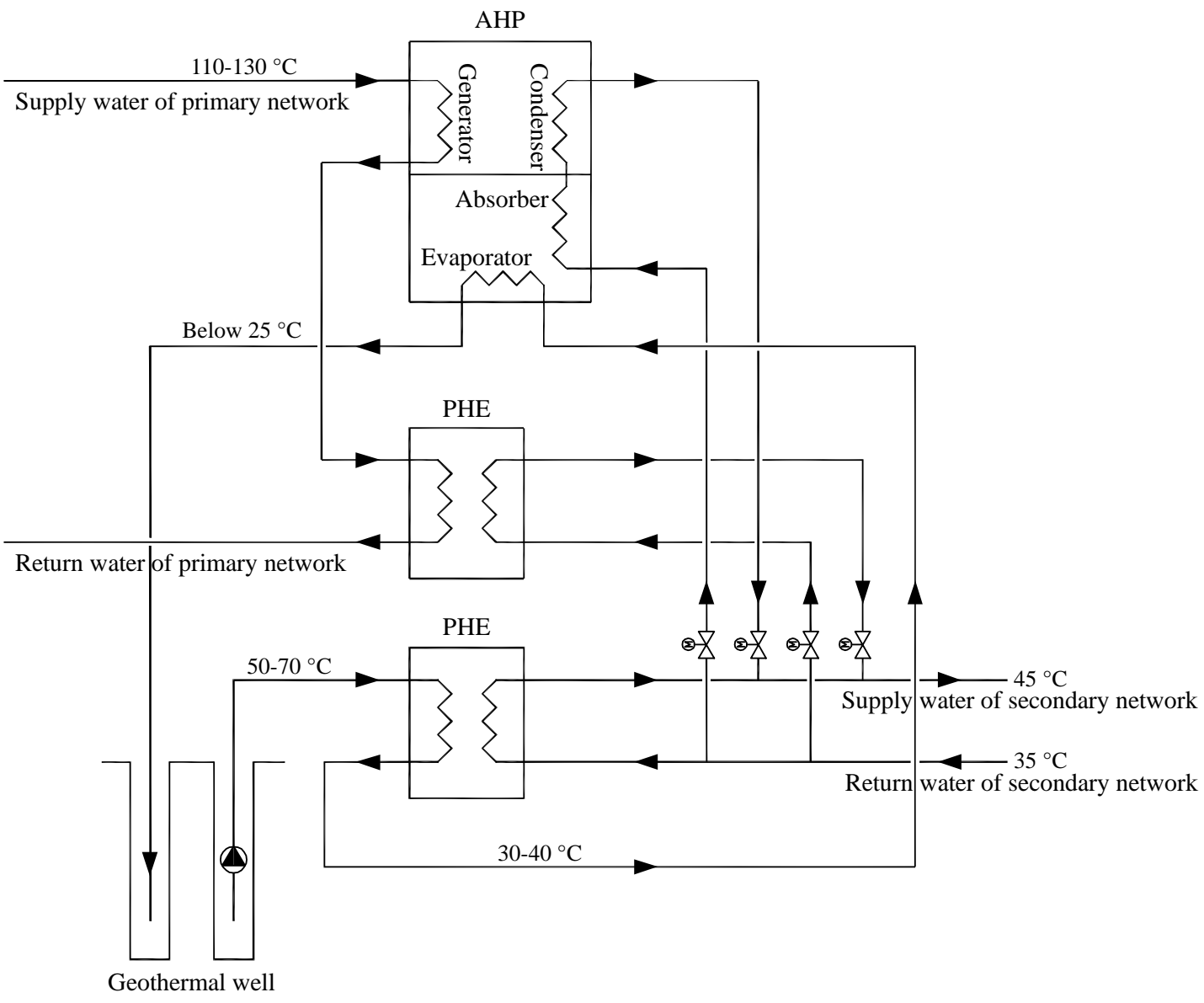

Fig. 1. Schematic drawing of the CDHS

In this substation, the geothermal water is used in stages: Stage 1: the geothermal water with temperature around $50-70^{\circ} \mathrm{C}$ supplies heat to consumers by giving heat to the secondary network; Stage 2: the cooled geothermal water with temperature around $30-40^{\circ} \mathrm{C}$ exchanges heat in the evaporator of the AHP, and is recharged at temperature below $25^{\circ} \mathrm{C}$. By this gradient utilization, the CDHS can get more heat from the geothermal water than the single-stage geothermal system, of which the recharge temperature is about $30-40^{\circ} \mathrm{C}$.

\section{Mathematical modeling}

The overall mathematical model of the CDHS included two parts, i.e. the AHP and the PHE. These sub-models were established according to the laws of energy conservation and mass conservation [25]. When building the models, some 
fundamental assumptions were made, according to $[25,26]$ :

1) The substation was in thermodynamic equilibrium and steady state, and heat losses to the environment were neglectable.

2) The working fluid was in thermodynamic equilibrium and saturated state when coming out of the evaporator and the condenser.

3) The solution of $\mathrm{LiBr}$ was in saturated state when coming out of the generator and the absorber.

4) Flow resistance, heat losses and pressure losses were neglectable.

5) The enthalpy of working fluid was constant during the throttling process.

6) The power consumptions of both solution pump and working fluid pump were neglectable.

7) All heat transfer units worked in a countercurrent process, and the logarithmic mean temperature difference method was used to calculate heat transfer.

\subsection{Mathematical model of the AHP}

A schematic drawing of the AHP is shown in Fig. 2. This is a single-effect LiBr$\mathrm{H}_{2} \mathrm{O}$ absorption heat pump. It mainly consists of 4 vessels: evaporator, absorber, condenser and generator. The working principle of this single-effect $\mathrm{LiBr}-\mathrm{H}_{2} \mathrm{O}$ absorption heat pump is divided into solution circulation and working fluid circulation.

a) Solution circulation: weak solution goes from State Point 5 to State Point 6. Water vapor is separated out in the generator, and the solution becomes stronger. Strong solution goes from State Point 8 to State Point 5, and becomes weaker. Then the next solution circulation begins.

b) Working fluid circulation: water vapor goes from State Point 2 to State Point 3, after which it is absorbed by weak solution and goes back to the generator. Then the 
next working fluid circulation begins.

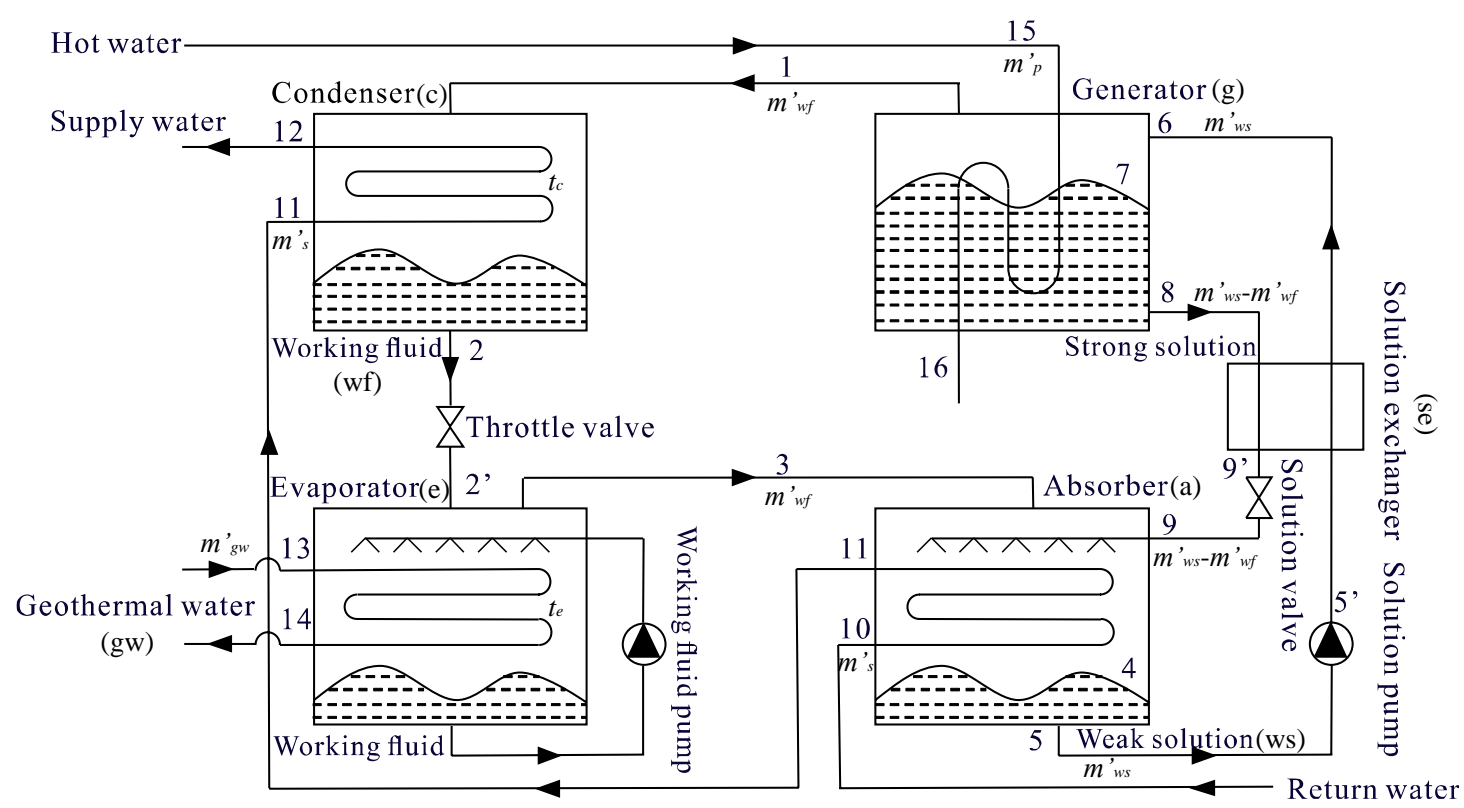

Fig. 2. Schematic drawing of the AHP

1) Mathematical modeling for the generator

In the generator, weak solution (State Point 6) of $\mathrm{LiBr}$ is heated to be saturated (State Point 7) by hot water. Working fluid $\left(\mathrm{H}_{2} \mathrm{O}\right)$ is evaporated into water vapor (State Point 1) and enters the condenser. Then weak solution becomes strong solution (State Point 8) and leaves the generator.

The energy conservation equations for the generator are given as follows, according to $[24,25]$,

$$
\begin{gathered}
Q_{g, 1}^{\prime}=Q_{g, 2}^{\prime} \\
Q_{g, 1}^{\prime}=\left(m^{\prime}{ }_{w s}-m^{\prime}{ }_{w f}\right) h_{8}+m^{\prime}{ }_{w f} h_{1}-m^{\prime}{ }_{w s} h_{6} \\
Q_{g, 2}^{\prime}=m_{p}^{\prime} c_{p}\left(t_{15}-t_{16}\right)
\end{gathered}
$$

where $m_{w s}^{\prime}$ stands for the mass flow rate of weak solution, $m_{w f}^{\prime}$ stands for mass flow rate of working fluid, $m^{\prime}{ }_{p}$ stands for mass flow rate of the primary network and $h$ stands for the working substance's enthalpy at the state points in Fig. 2. 
The mass conservation equation for the generator is given as follow, according to $[24,25]$,

$$
m_{w s}^{\prime} x_{6}=\left(m_{w s}^{\prime}-m_{w f}^{\prime}\right) x_{8}
$$

where $x$ stands for solution's concentration at the state points in Fig. 2.

The heat transfer equations for the generator are given as follows, according to [25, 27],

$$
\begin{gathered}
Q_{g, 1}^{\prime}=Q_{g, 3}^{\prime} \\
Q_{g, 3}^{\prime}=U_{g} A_{g} \frac{\left(t_{15}-t_{8}\right)-\left(t_{16}-t_{7}\right)}{\ln \frac{t_{15}-t_{8}}{t_{16}-t_{7}}}
\end{gathered}
$$

where $U_{g}$ stands for heat transfer coefficient of the generator and $A_{g}$ stands for heat transfer area of the generator.

2) Mathematical modeling for the absorber

In the absorber, strong solution (State Point 9) absorbs water vapor (State Point 3) generated in the evaporator and releases heat to the return water of secondary network. Then strong solution becomes weak solution (State Point 5) and leaves the absorber.

The energy conservation equations for the absorber are given as follows, according to $[24,25]$,

$$
\begin{gathered}
Q_{a, 1}^{\prime}=Q_{a, 2}^{\prime} \\
Q_{a, 1}^{\prime}=\left(m^{\prime}{ }_{w s}-m^{\prime}{ }_{w f}\right) h_{9}+m^{\prime}{ }_{w f} h_{3}-m^{\prime}{ }_{w s} h_{5} \\
Q_{a, 2}^{\prime}=m^{\prime}{ }_{s} c_{p}\left(t_{11}-t_{10}\right)
\end{gathered}
$$

where $m^{\prime}{ }_{s}$ stands for the mass flow rate of the secondary network.

The mass conservation equation for the absorber is given as follow, according to $[24,25]$ 


$$
m^{\prime}{ }_{w s} x_{5}=\left(m^{\prime}{ }_{w s}-m^{\prime}{ }_{w f}\right) x_{9}
$$

The heat transfer equations for the absorber are given as follows, according to [25, 27],

$$
\begin{gathered}
Q_{a, 1}^{\prime}=Q_{a, 3}^{\prime} \\
Q_{a, 3}^{\prime}=U_{a} A_{a} \frac{\left(t_{9}-t_{10}\right)-\left(t_{5}-t_{11}\right)}{\ln \frac{t_{9}-t_{10}}{t_{5}-t_{11}}}
\end{gathered}
$$

3) Mathematical modeling for the condenser

In the condenser, water vapor (State Point 1) is condensed to fluid (State Point 2) and releases heat. This heat is then absorbed by the secondary network.

The energy conservation equations for the condenser are given as follows, according to $[24,25]$,

$$
\begin{gathered}
Q_{c, 1}^{\prime}=Q_{c, 2}^{\prime} \\
Q_{c, 1}^{\prime}=m_{w f}^{\prime}\left(h_{1}-h_{2}\right) \\
Q_{c, 2}^{\prime}=m_{s}^{\prime} c_{p}\left(t_{12}-t_{11}\right)
\end{gathered}
$$

The heat transfer equations for the condenser are given as follows, according to $[25,27]$

$$
\begin{gathered}
Q_{c, 1}^{\prime}=Q_{c, 3}^{\prime} \\
Q_{c, 3}^{\prime}=U_{c} A_{c} \frac{t_{12}-t_{11}}{\ln \frac{t_{c}-t_{11}}{t_{c}-t_{12}}}
\end{gathered}
$$

where $t_{c}$ stands for the condensation temperature.

4) Mathematical modeling for the evaporator

The saturated working fluid (State Point 2) becomes a mixture of saturated water 
and saturated water vapor (State Point 2') after passing through the throttle valve. Then the mixture enters the evaporator and evaporates to saturated water vapor (State Point $3)$.

The energy conservation equations for the evaporator are given as follows, according to $[24,25]$,

$$
\begin{gathered}
Q_{e, 1}^{\prime}=Q_{e, 2}^{\prime} \\
Q_{e, 1}^{\prime}=m^{\prime}{ }_{w f}\left(h_{3}-h_{2}\right) \\
Q_{e, 2}^{\prime}=m_{g w}^{\prime} c_{p}\left(t_{13}-t_{14}\right)
\end{gathered}
$$

where $m_{g w}^{\prime}$ stands for the mass flow rate of geothermal water.

The heat transfer equations for the evaporator are given as follows, according to $[25,27]$,

$$
\begin{gathered}
Q_{e, 1}^{\prime}=Q_{e, 3}^{\prime} \\
Q_{e, 3}^{\prime}=U_{e} A_{e} \frac{t_{13}-t_{14}}{\ln \frac{t_{13}-t_{e}}{t_{14}-t_{e}}}
\end{gathered}
$$

where $t_{e}$ stands for the evaporation temperature.

5) Mathematical modeling for the solution exchanger

Weak solution (State Point 5) from the absorber exchanges heat with strong solution (State Point 8) from the generator in the solution exchanger. In this process, weak solution is preheated to save energy consumed in the generator. Strong solution is cooled down to enable it absorb more water vapor in the absorber.

The energy conservation equations for the solution exchanger are given as follows, according to $[24,25]$,

$$
Q_{s e, 1}^{\prime}=Q_{s e, 2}^{\prime}
$$




$$
\begin{gathered}
Q_{s e, 1}^{\prime}=\left(m^{\prime}{ }_{w s}-m^{\prime}{ }_{w f}\right)\left(h_{8}-h_{9}\right) \\
Q_{s e, 2}^{\prime}=m_{w s}^{\prime}\left(h_{6}-h_{5}\right)
\end{gathered}
$$

The heat transfer equations for the solution exchanger are given as follows, according to $[25,27]$,

$$
\begin{gathered}
Q_{s e, 1}^{\prime}=Q_{s e, 3}^{\prime} \\
Q_{s e, 3}^{\prime}=U_{s e} A_{s e} \frac{\left(t_{8}-t_{6}\right)-\left(t_{9}-t_{5}\right)}{\ln \frac{t_{8}-t_{6}}{t_{9}-t_{5}}}
\end{gathered}
$$

6) Coefficient of Performance (COP) of the AHP

COP is defined as the ratio of heating capacity of the AHP to heat consumed by the AHP [25]. For the system discussed in this paper, it is calculated by Equation 28,

$$
C O P=\frac{Q_{A H P}^{\prime}}{Q_{g}^{\prime}}=\frac{Q_{a}^{\prime}+Q_{c}^{\prime}}{Q_{g}^{\prime}}=\frac{Q_{g}^{\prime}+Q_{e}^{\prime}}{Q_{g}^{\prime}}
$$

where $Q^{\prime}{ }_{A H P}$ stands for heating capacity of the AHP.

7) Circulation ratio of the solution

Circulation ratio of the solution represents the number of refrigerant-absorbent mass required for each $1 \mathrm{~kg}$ refrigerant produced in the AHP [25, 27], defined by Equation 29 in this study,

$$
D=\frac{m_{w s}^{\prime}}{m_{w f}^{\prime}}
$$

where $D$ stands for circulation ratio of the solution.

\subsection{Mathematical model of the PHE}

A schematic drawing of the PHE is shown in Fig. 3. The operational principle of the PHE is that hot fluid and cold fluid flow in opposite directions on either side of the 
plate and exchange heat through the plate.

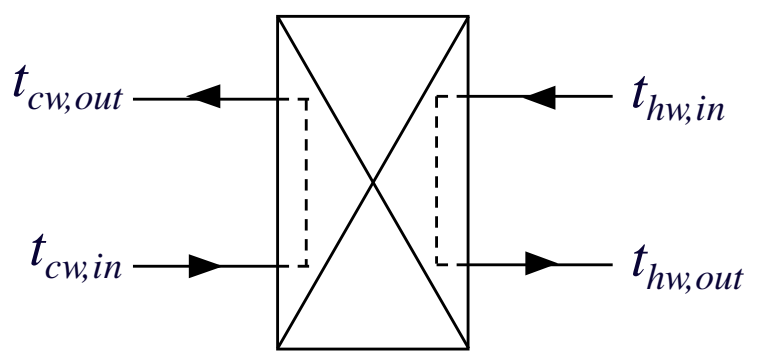

Fig. 3. Schematic drawing of the PHE

The energy conservation equations for the PHE are given as follows, according to $[28]$,

$$
\begin{gathered}
Q_{p h e, 1}^{\prime}=Q_{p h e, 2}^{\prime} \\
Q_{p h e, 1}^{\prime}=m_{h w}^{\prime} C_{p, h w}\left(t_{h w, \text { in }}-t_{h w, \text { out }}\right) \\
Q_{p h e, 2}^{\prime}=m_{c w}^{\prime} C_{p, c w}\left(t_{c w, o u t}-t_{c w, \text { in }}\right)
\end{gathered}
$$

where $m_{h w}^{\prime}$ stands for mass flow rate of hot water and $m_{c w}^{\prime}$ stands for mass flow rate of cold water.

The heat transfer equations for the PHE are given as follows [28].

$$
\begin{gathered}
Q_{p h e, 1}^{\prime}=Q_{p h e, 3}^{\prime} \\
Q_{p h e, 3}^{\prime}=U_{p h e} A_{p h e} \frac{\left(t_{h w, \text { in }}-t_{c w, \text { out }}\right)-\left(t_{h w . \text { out }}-t_{c w, \text { in }}\right)}{\ln \frac{t_{h w, \text { in }}-t_{c w, \text { out }}}{t_{h w, \text { out }}-t_{c w, \text { in }}}}
\end{gathered}
$$

\subsection{Solving mathematical models}

The core part of the CDHS model was the AHP. The whole process was done in MATLAB, a commercial mathematical tool. In the calculation, temperature, pressure and concentration equations for the $\mathrm{LiBr}$ solution were obtained from the studies carried by Kaita [29] and McNeely [30]; enthalpy equation of the LiBr solution came from ASHRAE handbook-1981 [31]; saturated pressure, saturated temperature and saturated 
enthalpy of $\mathrm{H}_{2} \mathrm{O}$ were available in IAPWS-IF97 [32].

1) Solving the AHP model

A schematic drawing of the solving process for the AHP is shown in Fig. 4. By solving the AHP mathematical model, the thermal process is simulated.

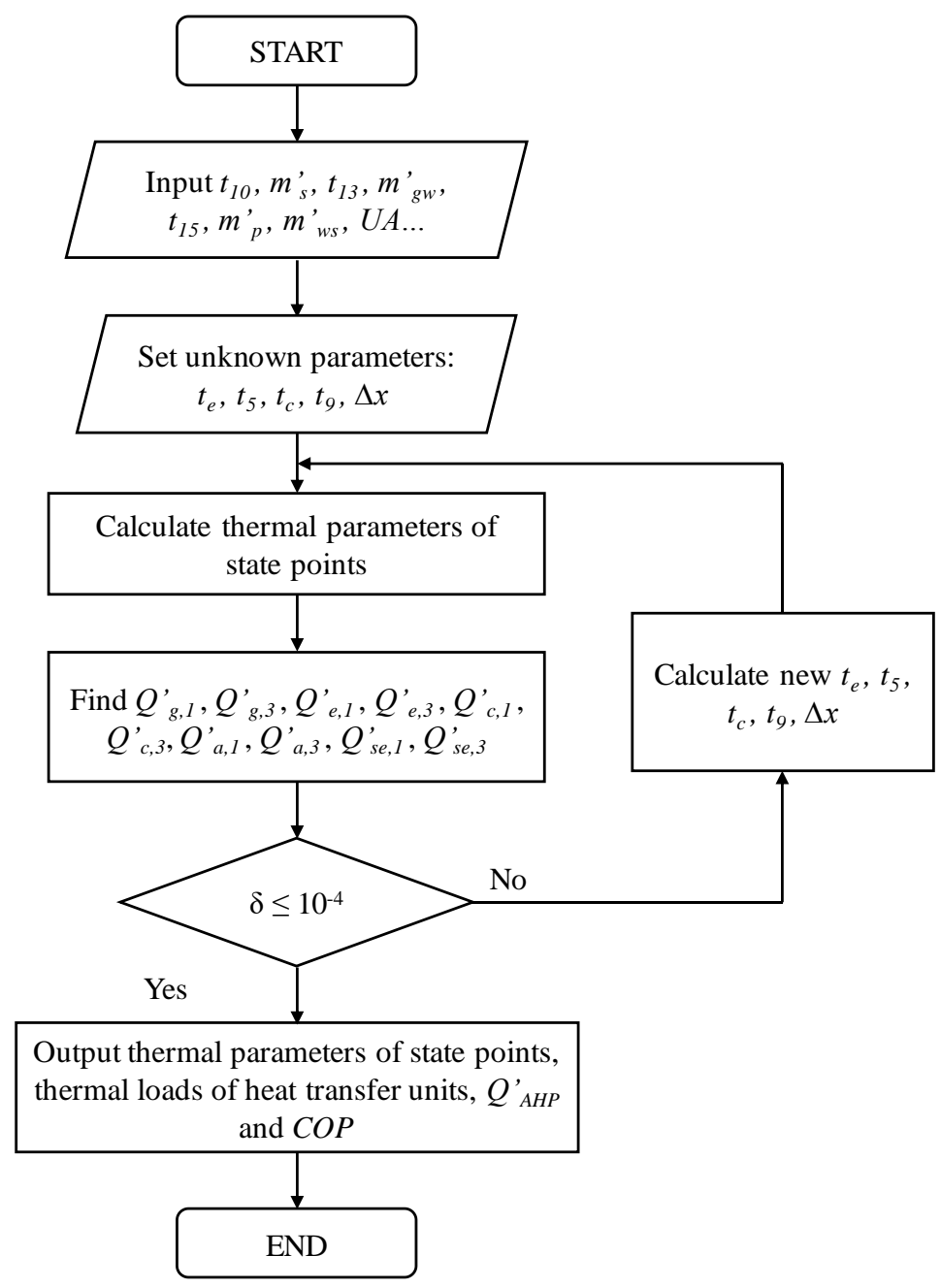

Fig. 4. A schematic drawing to show the solving process for the AHP

Main inputs used are listed as followings:

- Temperature $t_{10}$ and mass flow rate $m_{s}^{\prime}$ of the return secondary water.

- Temperature $t_{13}$ and mass flow rate $m_{g w}^{\prime}$ of the supply geothermal water.

- Temperature $t_{15}$ and mass flow rate $m^{\prime}{ }_{p}$ of the supply primary water. 
- Mass flow rate of the weak solution $m^{\prime}{ }_{w s}$.

- Product of heat transfer coefficient and heat transfer area of the heat transfer unit $U A$.

Additionally, there were some unknown parameters where assumptions for the starting values for the iteration were needed:

- Evaporation temperature $t_{e}$.

- Temperature of the weak solution at the absorber outlet $t_{5}$.

- Condensation temperature $t_{c}$.

- Temperature of the strong solution at the absorber inlet $t_{9}$.

- Concentration difference between the weak solution and the strong solution $\Delta x$.

Thermal parameters of state points were then be calculated based on the constitutive equations of $\mathrm{LiBr}$ and $\mathrm{H}_{2} \mathrm{O}$, including temperature, pressure, enthalpy, concentration and mass flow rate. Then the thermal load $Q^{\prime}$ of each heat transfer unit in the preceding equations was obtained. According to the heat transfer equations above, $Q_{i, 1}^{\prime}=Q_{i, 3}^{\prime}$, where $i$ could be $g, e, c, a$ and $s e$. Therefore, the difference between $Q_{i, 1}^{\prime}$ and $Q_{i, 3}^{\prime}$ was the objective, which was evaluated in each step. If the mean-square error of them was larger than $10^{-4}$, re-calculate $t_{e}, t_{5}, t_{c}, t_{9}, \Delta x$ by the lsqnonlin function in MATLAB, which can make mean-square error the smallest. Define the following mean-square error $\delta$,

$$
\delta=\sqrt{\sum\left(Q_{i, 1}^{\prime}-Q^{\prime}{ }_{i, 3}\right)^{2}}
$$

For this calculation work, its main outputs included thermal parameters of state points, thermal loads of heat transfer units, $Q^{\prime}{ }_{A H P}$ and $C O P$. 
2) Solving the CDHS model

A schematic drawing of the solving process for the CDHS is shown in Fig. 5. In the simulation, $Q_{\text {part }}^{\prime}$ stands for required heating capacity of the AHP under different loads.

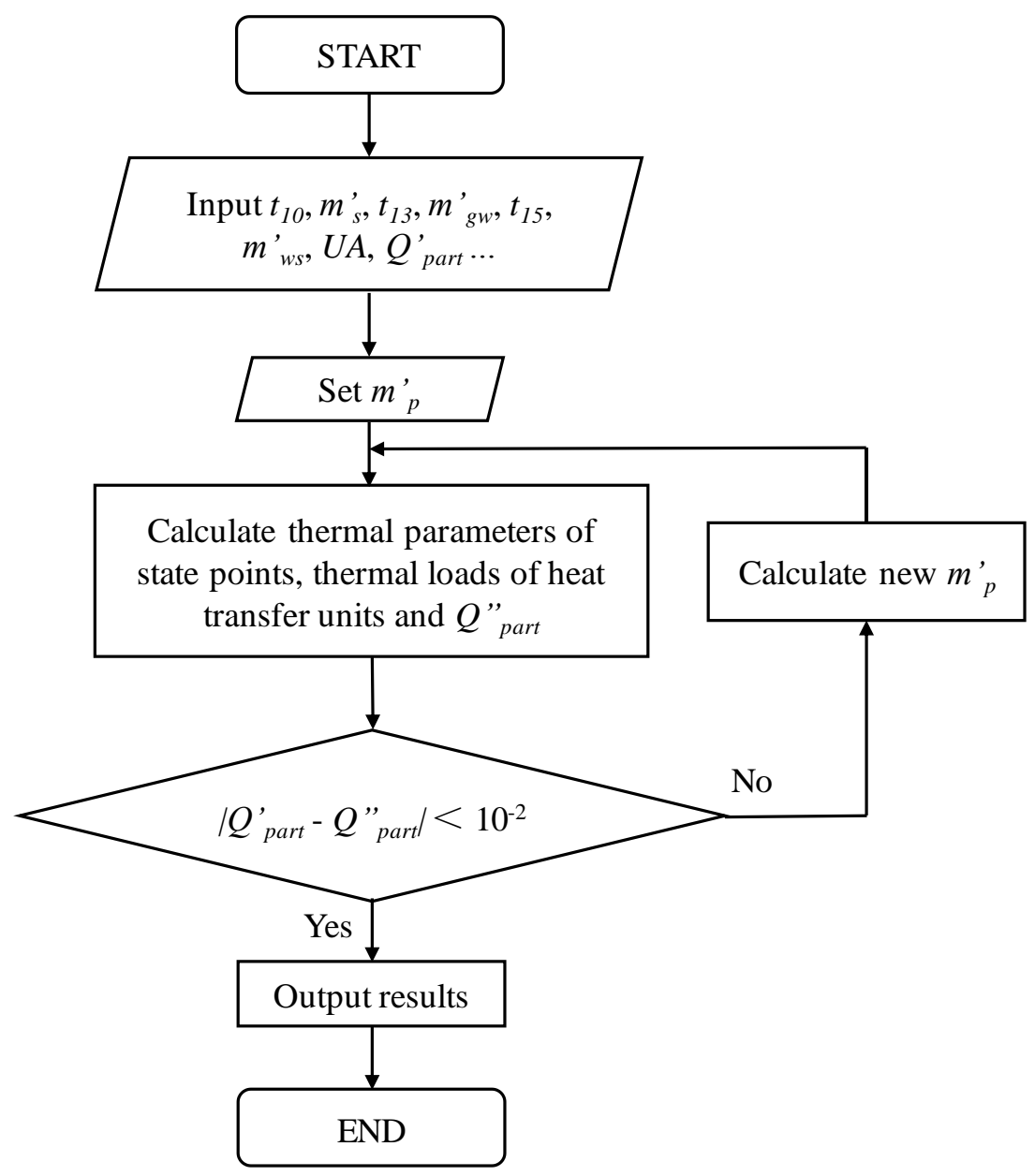

Fig. 5. A schematic drawing to show the solving process for the CDHS

In this calculation, main inputs included $t_{10}, m_{s}^{\prime}, t_{13}, m_{g w}^{\prime}, t_{15}, m_{w s}^{\prime}, U A$ and $Q_{\text {part }}^{\prime}$, in which $t_{13}$ was obtained by the mathematical model of the PHE. The unknown parameter that needed an initial assumption was $m_{p}{ }_{p}$. From the mathematical model of the AHP, thermal parameters of state points, thermal loads of heat transfer units and $Q^{\prime \prime}{ }_{\text {part }}$ could be obtained, where $Q^{\prime \prime}{ }_{\text {part }}$ stands for the calculated $Q_{\text {part }}^{\prime}$. As $Q_{\text {part }}^{\prime}=Q^{\prime \prime}{ }_{\text {part }}$ in theory, the difference between $Q_{\text {part }}^{\prime}$ and $Q_{\text {part }}^{\prime \prime}$ was the objective, 
which should be evaluated in each step. If the difference was no smaller than $10^{-2}$, recalculate $m_{p}^{\prime}$ by the lsqnonlin function in MATLAB. At last, all the simulation results can be output.

\section{Case study}

A case study of this CDHS has been conducted for a real business center in Tianjin, China. The center had two geothermal wells, one for extraction and one for recharge. The mass flow rate of the well was $30 \mathrm{~kg} / \mathrm{s}$ and the extraction temperature of hot water was $60^{\circ} \mathrm{C}$. The heating was achieved by floor radiation heating and design return/supply temperatures were $35^{\circ} \mathrm{C} / 45^{\circ} \mathrm{C}$. The heat transfer area on the geothermal water side was $120 \mathrm{~m}^{2}$. The geothermal water temperature at the AHP inlet was $37^{\circ} \mathrm{C}$.

The design conditions of major parameters were defined as $t_{15}=110^{\circ} \mathrm{C},{m_{p}^{\prime}}_{p}=60$ $\mathrm{kg} / \mathrm{s}, \quad t_{13}=37{ }^{\circ} \mathrm{C}, \quad t_{14}=19{ }^{\circ} \mathrm{C}, \quad m_{g w}^{\prime}=30 \mathrm{~kg} / \mathrm{s}, \quad t_{10}=35^{\circ} \mathrm{C}, \quad t_{12}=45^{\circ} \mathrm{C}$. The design temperature differences in AHP units were $\Delta t_{e}=t_{14}-t_{e}=2{ }^{\circ} \mathrm{C}, \Delta t_{c}=t_{c}-t_{12}=5^{\circ} \mathrm{C}$, $\Delta t_{g}=t_{8}-t_{16}=3{ }^{\circ} \mathrm{C}, \Delta t_{a}=t_{5}-t_{11}=5{ }^{\circ} \mathrm{C}, \Delta t_{s e}=t_{6}-t_{5}=20{ }^{\circ} \mathrm{C}$. By substituting these parameters into the AHP model introduced in Section 3, thermal parameters of typical state points under design conditions were derived, as listed in Table 1. As the assumptions in Section 3, the desuperheating in the condenser was ignored. So the outlet temperature of the condenser was taken as the condensation temperature, not the inlet temperature.

\section{Table 1}

Thermal parameters of typical state points at design condition

\begin{tabular}{llcccccc}
\hline State & \multirow{2}{*}{ Substance } & Location & Temperature & Pressure & Enthalpy & Concentration & Mass flow rate \\
point & & $\left({ }^{\circ} \mathrm{C}\right)$ & $(\mathrm{kPa})$ & $(\mathrm{kJ} / \mathrm{kg})$ & $(\%)$ & $(\mathrm{kg} / \mathrm{s})$ \\
\hline
\end{tabular}




\begin{tabular}{|c|c|c|c|c|c|c|c|}
\hline 1 & $\begin{array}{l}\text { Water } \\
\text { vapor }\end{array}$ & $\begin{array}{c}\text { Condenser } \\
\text { inlet }\end{array}$ & 92.2 & 12.3542 & 3107.1 & 0 & 0.96 \\
\hline 2 & Water & $\begin{array}{c}\text { Condenser } \\
\text { outlet }\end{array}$ & 50 & 12.3542 & 641.6 & 0 & 0.96 \\
\hline 3 & $\begin{array}{l}\text { Water } \\
\text { vapor }\end{array}$ & $\begin{array}{c}\text { Evaporator } \\
\text { outlet }\end{array}$ & 17 & 1.9386 & 2978.9 & 0 & 0.96 \\
\hline 4 & $\begin{array}{l}\text { Strong } \\
\text { solution }\end{array}$ & Absorber & 62.4 & 1.9386 & 318.8 & 61.8 & 6.14 \\
\hline 5 & $\begin{array}{l}\text { Weak } \\
\text { solution }\end{array}$ & $\begin{array}{c}\text { Absorber } \\
\text { outlet }\end{array}$ & 45.4 & 1.9386 & 294.2 & 53.43 & 7.10 \\
\hline 6 & $\begin{array}{l}\text { Weak } \\
\text { solution }\end{array}$ & $\begin{array}{c}\text { Generator } \\
\text { inlet }\end{array}$ & 73.4 & 12.3542 & 352.1 & 53.43 & 7.10 \\
\hline 7 & $\begin{array}{l}\text { Weak } \\
\text { solution }\end{array}$ & Generator & 82.9 & 12.3542 & 371.9 & 53.43 & 7.10 \\
\hline 8 & $\begin{array}{l}\text { Strong } \\
\text { solution }\end{array}$ & $\begin{array}{c}\text { Generator } \\
\text { outlet }\end{array}$ & 101.5 & 12.3542 & 391.4 & 61.8 & 6.14 \\
\hline 9 & $\begin{array}{l}\text { Strong } \\
\text { solution }\end{array}$ & $\begin{array}{c}\text { Absorber } \\
\text { inlet }\end{array}$ & 65.4 & 1.9386 & 324.3 & 61.8 & 6.14 \\
\hline
\end{tabular}

The $C O P$ of the AHP was 1.78 , and the mass flow rate of the secondary network on the AHP side was $123.25 \mathrm{~kg} / \mathrm{s}$, on the geothermal water side was $69.25 \mathrm{~kg} / \mathrm{s}$, and on the primary network side was $237.5 \mathrm{~kg} / \mathrm{s}$. For simplicity, the product of heat transfer area and heat transfer coefficient was used in the calculation, according to [24]. The structural parameters of AHP units are listed in Table 2.

\section{Table 2}

Structural parameters of AHP units

\begin{tabular}{|c|c|c|c|}
\hline Unit & $\begin{array}{c}Q^{\prime} \\
(\mathrm{kW})\end{array}$ & $\begin{array}{l}\text { Logarithmic mean temperature difference } \\
\qquad\left({ }^{\circ} \mathrm{C}\right)\end{array}$ & $\begin{array}{c}U A \\
(\mathrm{~kW} / \mathrm{K})\end{array}$ \\
\hline
\end{tabular}




\begin{tabular}{cccc}
\hline Generator & 2892.7 & 11.69 & 247.5 \\
Absorber & 2769.3 & 14.07 & 196.8 \\
Evaporator & 2249.8 & 7.79 & 288.6 \\
Condenser & 2373.2 & 7.05 & 336.5 \\
Solution exchanger & 411.5 & 23.8 & 17.3 \\
\hline
\end{tabular}

\section{Results and discussion}

\subsection{Performance analysis of the AHP}

When the outdoor temperature changes, the AHP is operated under part load to meet the consumers' demands. The Relative Heating Capacity (RHC) is the ratio of actual heating capacity to design heating capacity. The operational performance of AHP under different conditions are simulated, and the correlations between the RHC and important factors are shown in Fig. 6.

Fig. 6. (a) indicates that RHC of the AHP increases when the temperature of geothermal water at the evaporator inlet $t_{g w}$ is increasing. This is because of that higher evaporation temperature leads to higher evaporation and absorption pressure, which increases the evaporation capacity and the absorption capacity. Therefore, the heat absorbed from the geothermal water is also augmented. 


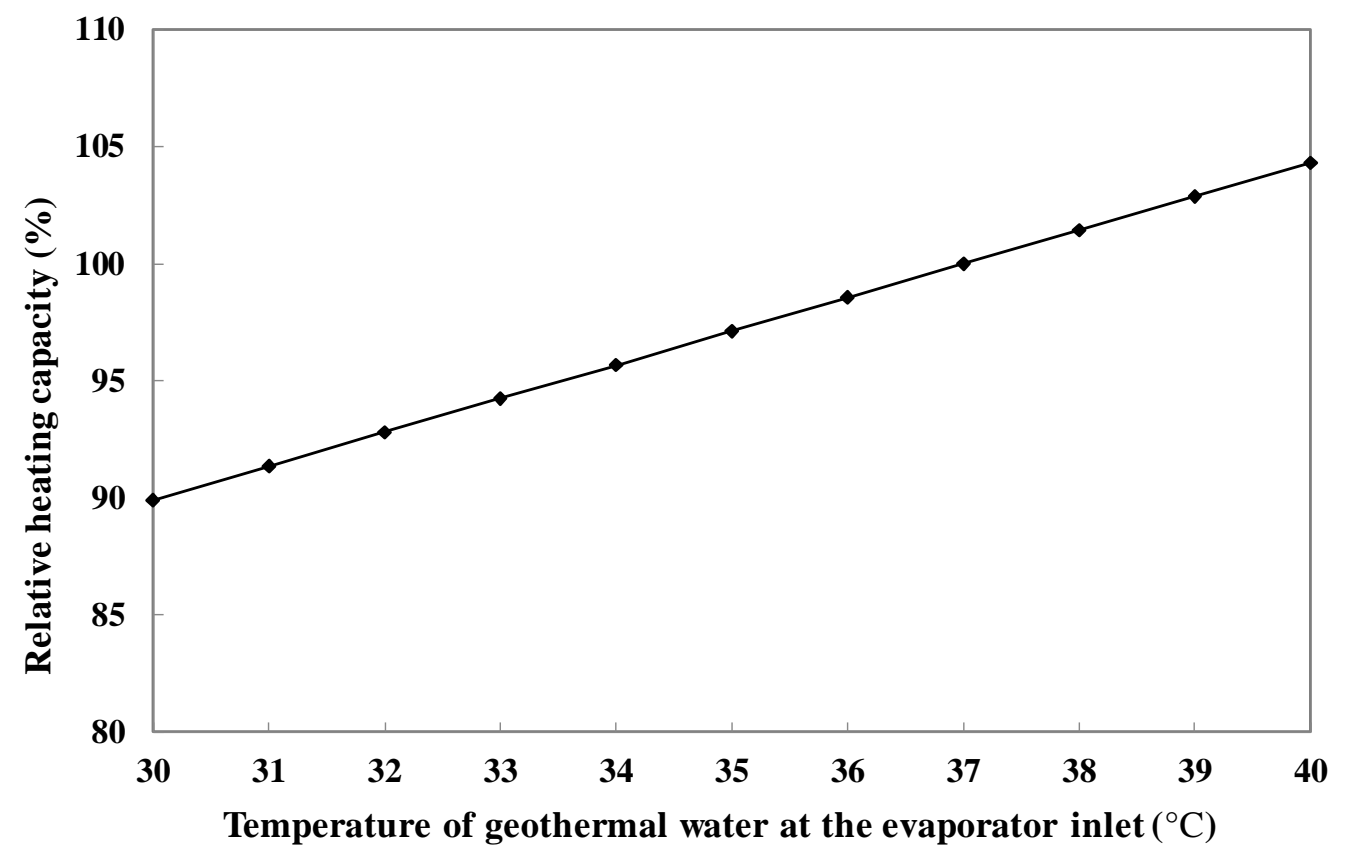

Among which $m^{\prime}{ }_{g w}=30 \mathrm{~kg} / \mathrm{s}, \quad t_{s}=35^{\circ} \mathrm{C}, \quad m^{\prime}{ }_{s}=430 \mathrm{~kg} / \mathrm{s}, \quad t_{p}=110^{\circ} \mathrm{C}, \quad m^{\prime}{ }_{p}=60 \mathrm{~kg} / \mathrm{s}$.

(a) Temperature of geothermal water at the evaporator inlet

Fig. 6. Operational performance of the AHP under different conditions

Fig. 6. (b) indicates that RHC of the AHP increases when the mass flow rate of geothermal water $m_{g w}^{\prime}$ is increasing. This is because of that higher $m_{g w}^{\prime}$ leads to higher logarithmic mean temperature difference with constant inlet temperature and higher heat transfer coefficient. Then more heat is transferred in the evaporator and more water vapor is produced, which increases the evaporation capacity and the absorption capacity. Therefore, the heat absorbed from the geothermal water is also augmented. 


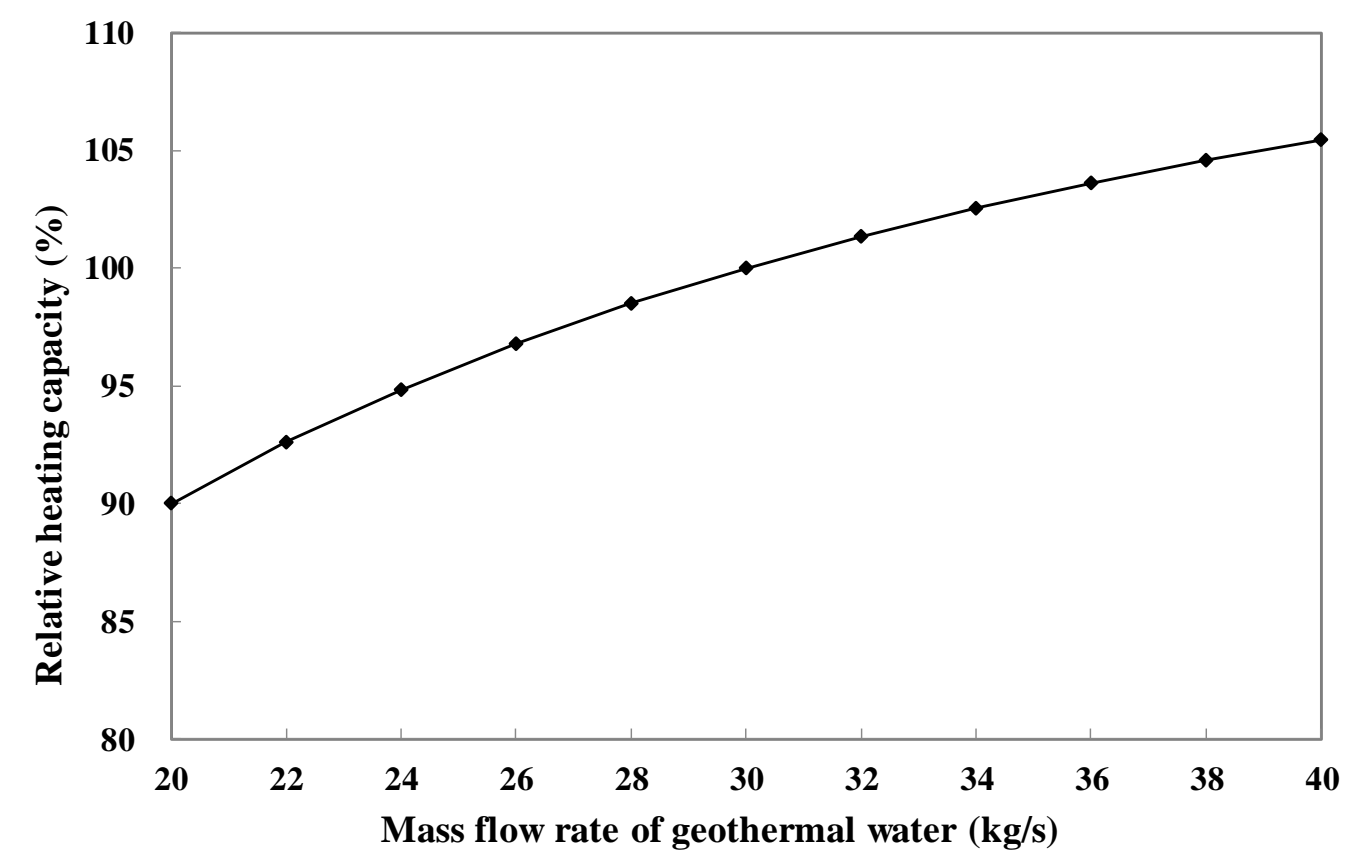

Among which $t_{g w}=37^{\circ} \mathrm{C}, t_{s}=35^{\circ} \mathrm{C}, m^{\prime}{ }_{s}=430 \mathrm{~kg} / \mathrm{s} . \quad t_{p}=110^{\circ} \mathrm{C}, m^{\prime}{ }_{p}=60 \mathrm{~kg} / \mathrm{s}$.

(b) Mass flow rate of geothermal water

Fig. 6. Operational performance of the AHP under different conditions

Fig. 6. (c) indicates that the RHC of the AHP decreases when the return temperature of the secondary network $t_{s}$ is increasing. This is because of that higher $t_{s}$ leads to higher condensation temperature and higher condensation pressure, which decreases the generation capacity. Therefore, the heat absorbed from the geothermal water is also reduced. 


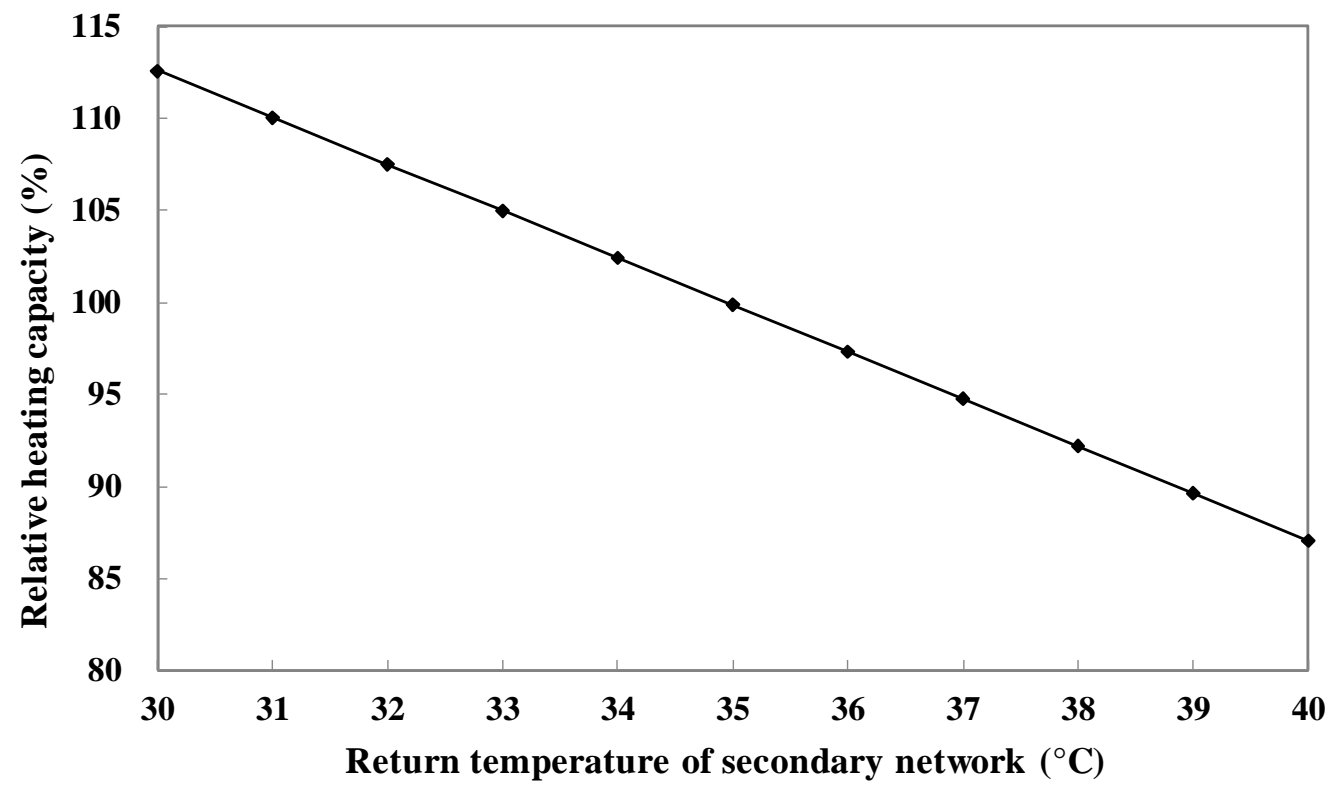

Among which $t_{g w}=37^{\circ} \mathrm{C}, m^{\prime}{ }_{g w}=30 \mathrm{~kg} / \mathrm{s}, \quad m^{\prime}{ }_{s}=430 \mathrm{~kg} / \mathrm{s}, \quad t_{p}=110^{\circ} \mathrm{C}, m_{p}^{\prime}=60 \mathrm{~kg} / \mathrm{s}$.

(c) Return temperature of secondary network

Fig. 6. Operational performance of the AHP under different conditions

Fig. 6. (d) indicates that the RHC of the AHP increases when the mass flow rate of primary network $m_{p}^{\prime}$ is increasing. This is because of that higher $m_{p}^{\prime}$ leads to higher logarithmic mean temperature difference with constant inlet temperature and higher heat transfer coefficient. Then more heat is transferred in the generator and more water vapor is produced, which increases the generation capacity and the absorption capacity. Therefore, the heat absorbed from the geothermal water is also augmented. 


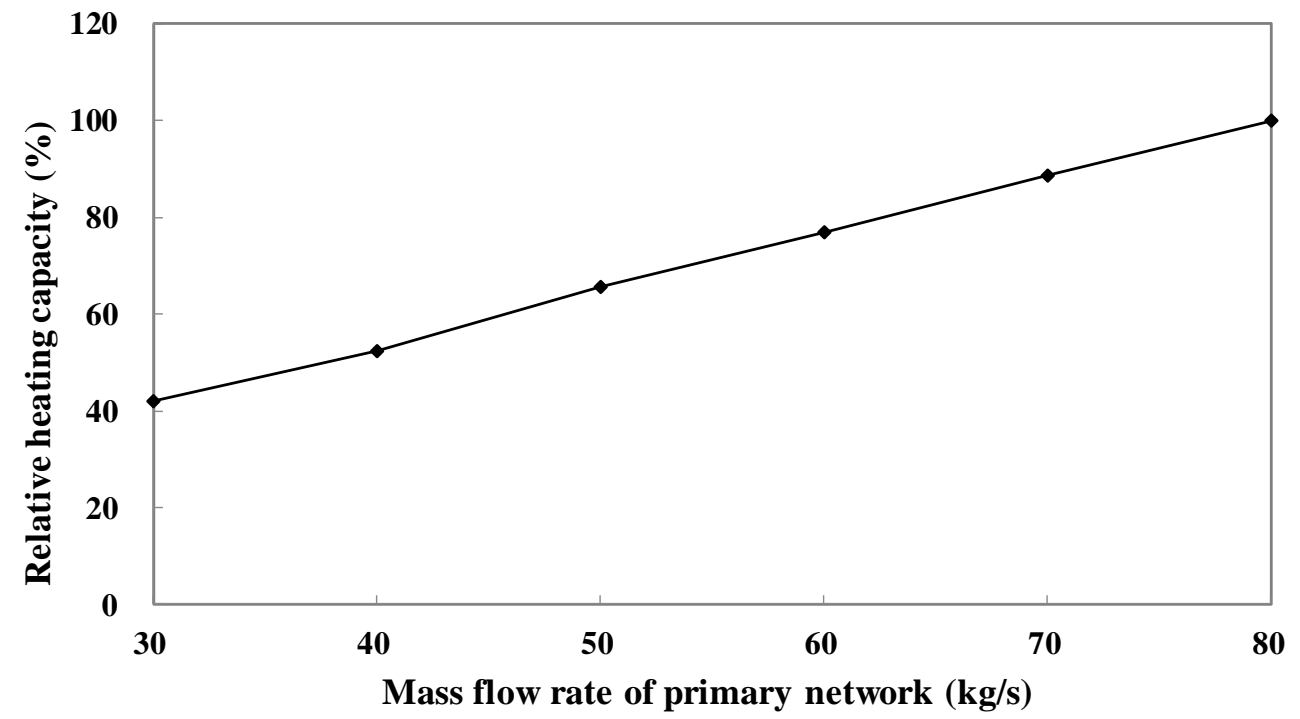

Among which $t_{g w}=37^{\circ} \mathrm{C}, m^{\prime}{ }_{g w}=30 \mathrm{~kg} / \mathrm{s}, t_{s}=35^{\circ} \mathrm{C}, m^{\prime}{ }_{s}=430 \mathrm{~kg} / \mathrm{s}, \quad t_{p}=110^{\circ} \mathrm{C}$.

(d) Mass flow rate of primary network

Fig. 6. Operational performance of the AHP under different conditions

\subsection{Operation regulation analysis of the CDHS}

In the operation regulation, flow regulation is usually used in the primary network and Temperature Regulation (TR) or Temperature Regulation with Flow Changing in stages (TRFC) are usually used in the secondary network. For the CDHS proposed in this study, the heating task at the secondary network is floor radiation heating. The thermal process of it can be calculated according to Technical specification for radiant heating and cooling JGJ 142-2012 [33]. Among which, both thermal load and mass flow rate of the floor radiation heating are variable during operation regulations. $\overline{Q^{\prime}}$ stands for relative thermal load, i.e. the ratio of actual thermal load to design thermal load. $\overline{m^{\prime}}$ stands for relative mass flow rate of secondary network, i.e. the ratio of actual mass flow rate to design flow rate. According to the results obtained in Section 5.1, the smallest relative heating capacity is 0.4 while making performance analysis of the AHP. Therefore, in this section, only the situation with $0.4 \leq \overline{Q^{\prime}} \leq 1$ is studied. It 
is calculated that outdoor temperature is $8^{\circ} \mathrm{C}$ when $\overline{Q^{\prime}}=0.4$ while it is $-7^{\circ} \mathrm{C}$ when $\overline{Q^{\prime}}=1$.

After coupling the model of floor radiation heating and the model of the CDHS, operational curves of the primary network and the geothermal water under different regulation methods could be obtained.

1) TR in secondary network

The results are shown in Fig. 7, where the medium temperature for primary network is the temperature at the AHP outlet and for geothermal water is the temperature at the PHE outlet.

Fig. 7. (a) shows that the required mass flow rate of primary network decreases when outdoor temperature increasing, indicating that to meet the thermal load of the secondary network a higher temperature difference in the primary network is required. Additionally, because of constant supply temperature, the return temperature of the primary network decreases.

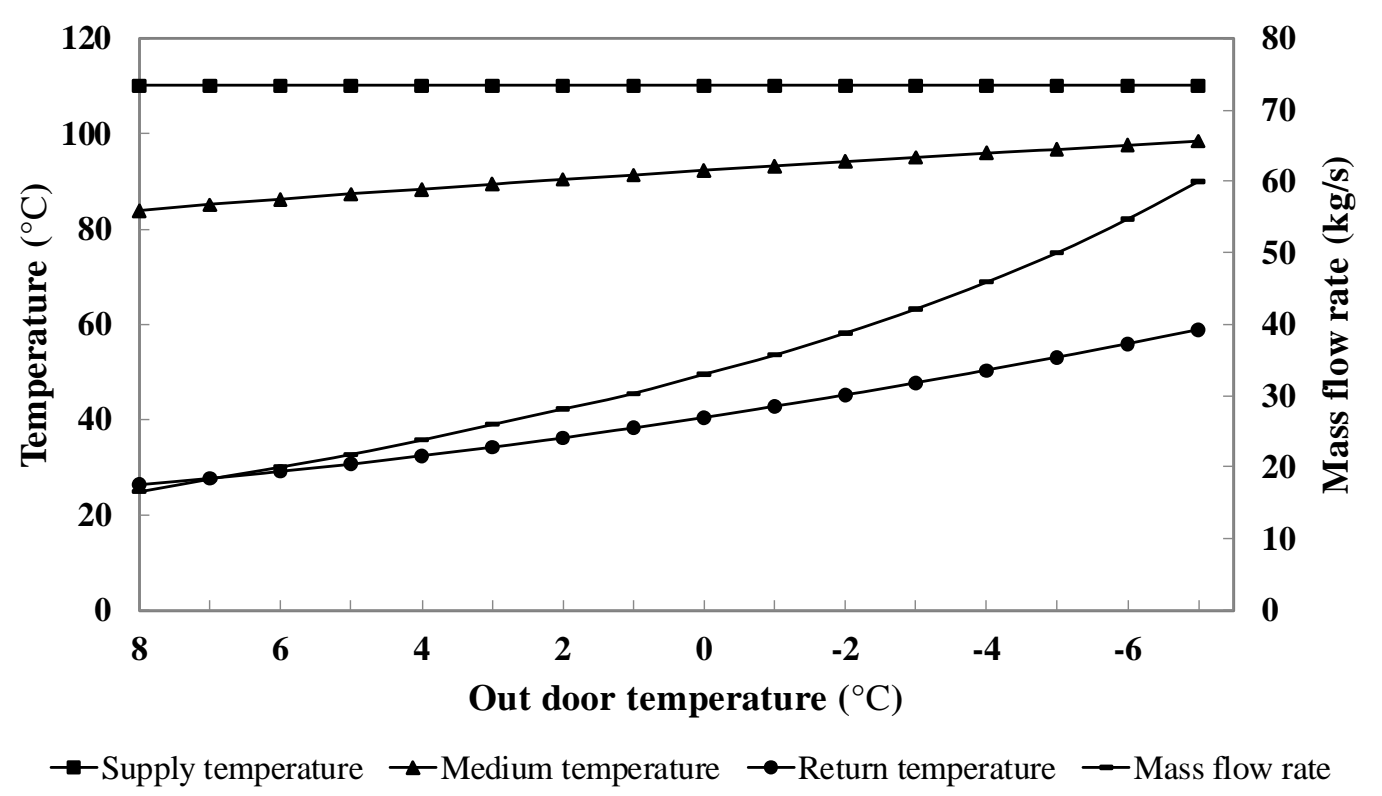

(a) Primary network

Fig. 7. Operational curves corresponding to TR in the secondary network 
Fig. 7. (b) shows that the required mass flow rate of geothermal water decreases when outdoor temperature increasing, indicating that the geothermal water is cooled down more in the PHE and the temperature of it at the AHP inlet decreases. Then the return temperature of geothermal water decreases and the geothermal energy is used more efficiently for the whole CDHS.

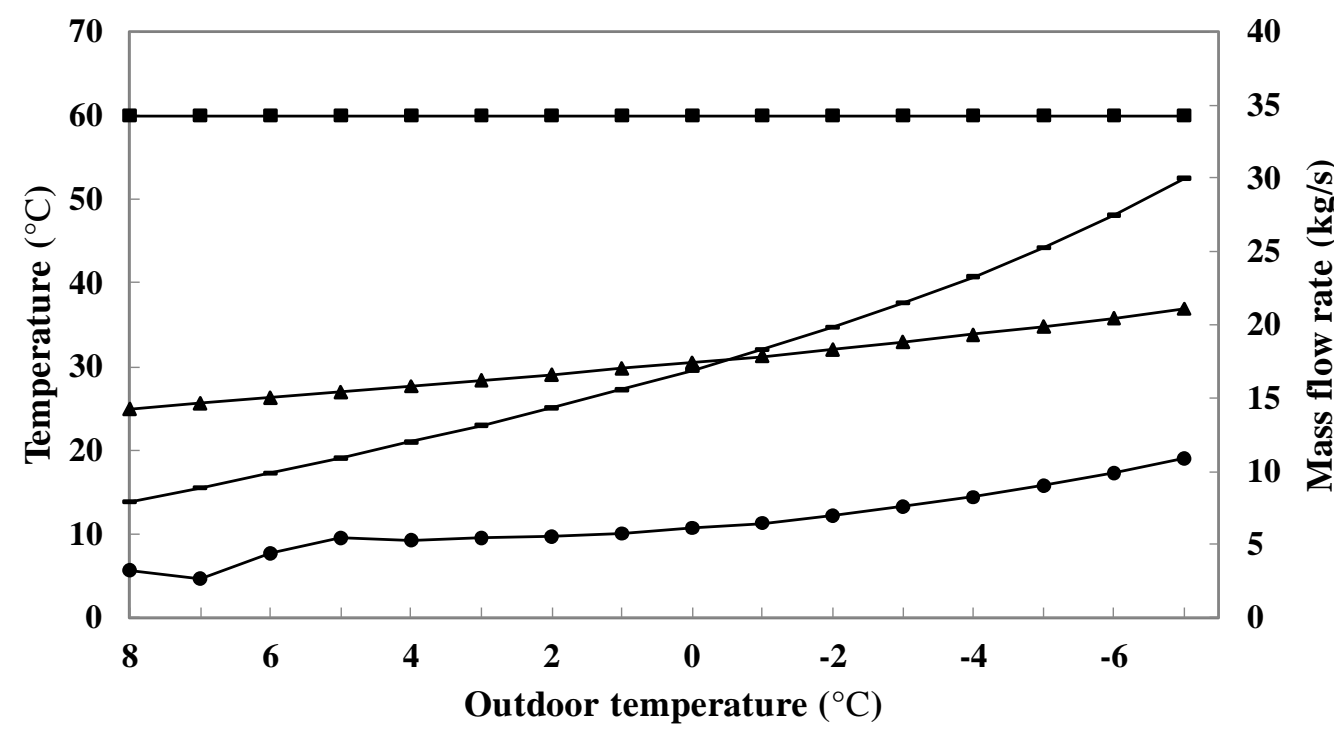

-Supply temperature $\rightarrow$ Medium temperature $\rightarrow$ - Return temperature $\longrightarrow$ Mass flow rate

(b) Geothermal water

Fig. 7. Operational curves corresponding to TR in secondary network

2) TRFC in the secondary network

Simulation results are shown in Fig. 8. TRFC has two stages: Stage 1 is $1^{\circ} \mathrm{C} \leq t_{\circ}$ $\leq 8^{\circ} \mathrm{C}\left(0.4 \leq \overline{Q^{\prime}} \leq 0.68\right)$ with $\overline{m^{\prime}}=0.7$, and Stage 2 is $-7^{\circ} \mathrm{C} \leq t_{o} \leq 1^{\circ} \mathrm{C}\left(0.68 \leq \overline{m^{\prime}} \leq 1\right)$ with $\overline{m^{\prime}}=1$, where $t_{o}$ stands for outdoor temperature.

Fig. 8. (a) shows that the required mass flow rate of primary network decreases when outdoor temperature increasing. And return temperature of primary network decreases, the same reason as TR. 


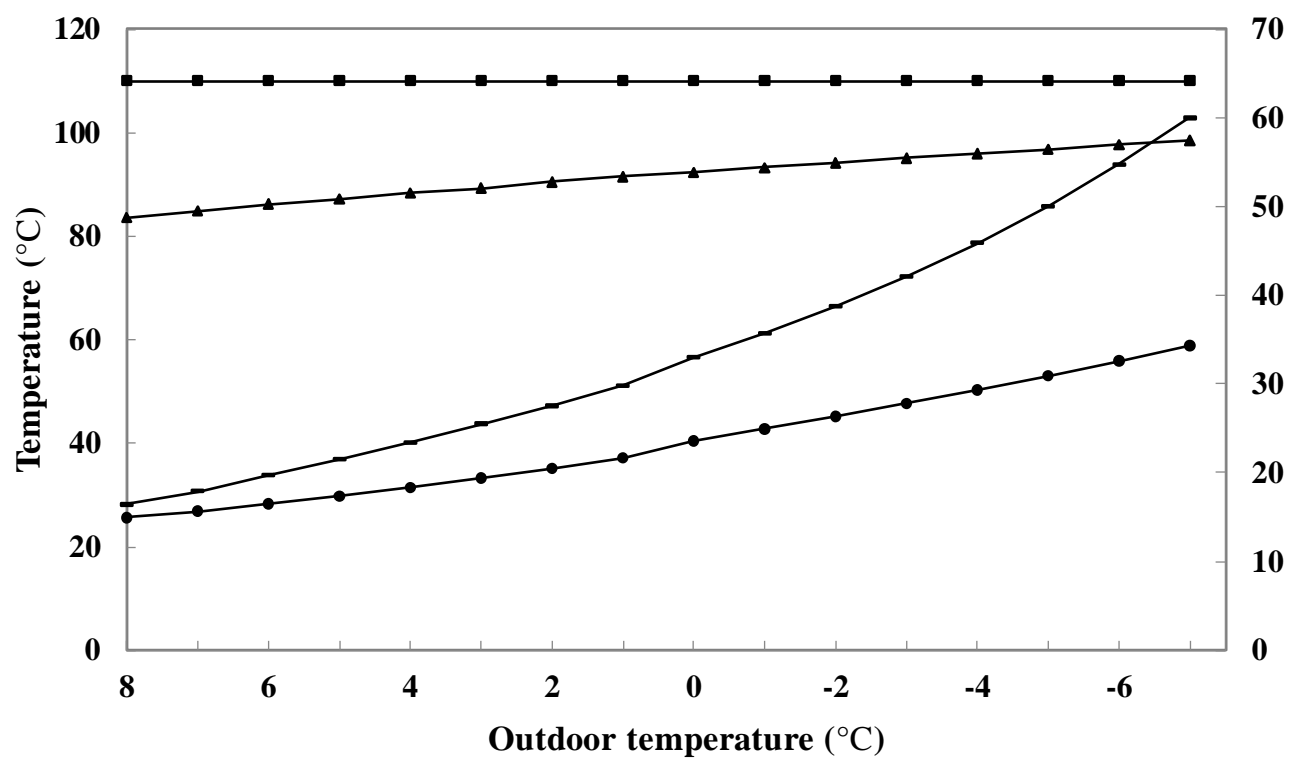

$\rightarrow$-Supply temperature $\rightarrow$-Medium temperature $\rightarrow$-Returen temperature $\rightarrow$ Mass flow rate

(a) Primary network

Fig. 8. Operational curves corresponding to TRFC in secondary network

Fig. 8. (b) shows that required mass flow rate of geothermal water decreases when outdoor temperature increasing. And return temperature of geothermal water decreases, the same reason as TR. On the other hand, return temperature of geothermal water has an apparent decline while $t_{o} \geq 1{ }^{\circ} \mathrm{C}$ with $\overline{m^{\prime}}=0.7$, indicating that efficiency of geothermal energy under TRFC is higher than the efficiency under TR.

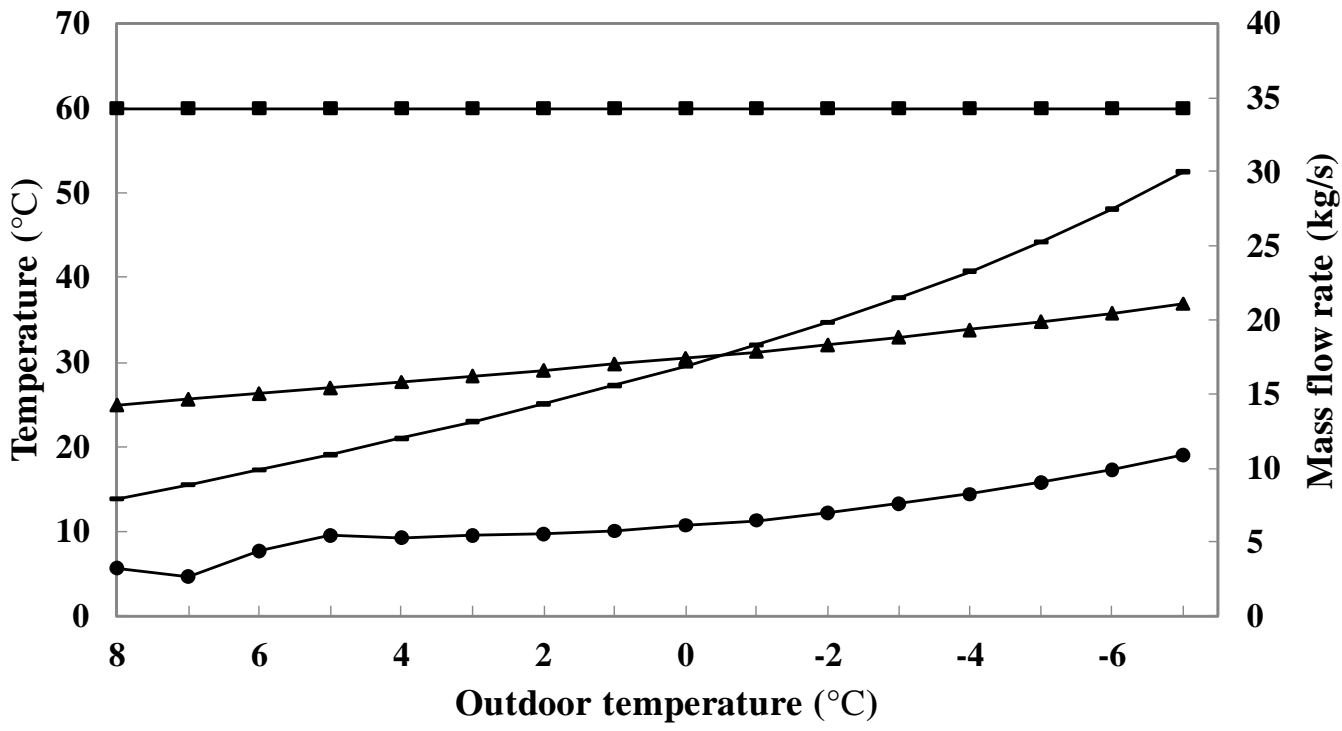

Supply temperature $\rightarrow$ Medium temperature $\rightarrow$-Return temperature $\longrightarrow$ Mass flow rate 
Fig. 8. Operational curves corresponding to TRFC in secondary network

3) Comparison of the two regulation methods

The comparison results are shown in Fig. 9.

Fig. 9. (a) shows that operation curves of TR and TRFC are almost coincident while $t_{o} \geq 1{ }^{\circ} \mathrm{C}$ with $\overline{m^{\prime}}=0.7$, indicating that the regulation methods have little influence on mass flow rate of primary network and geothermal water.

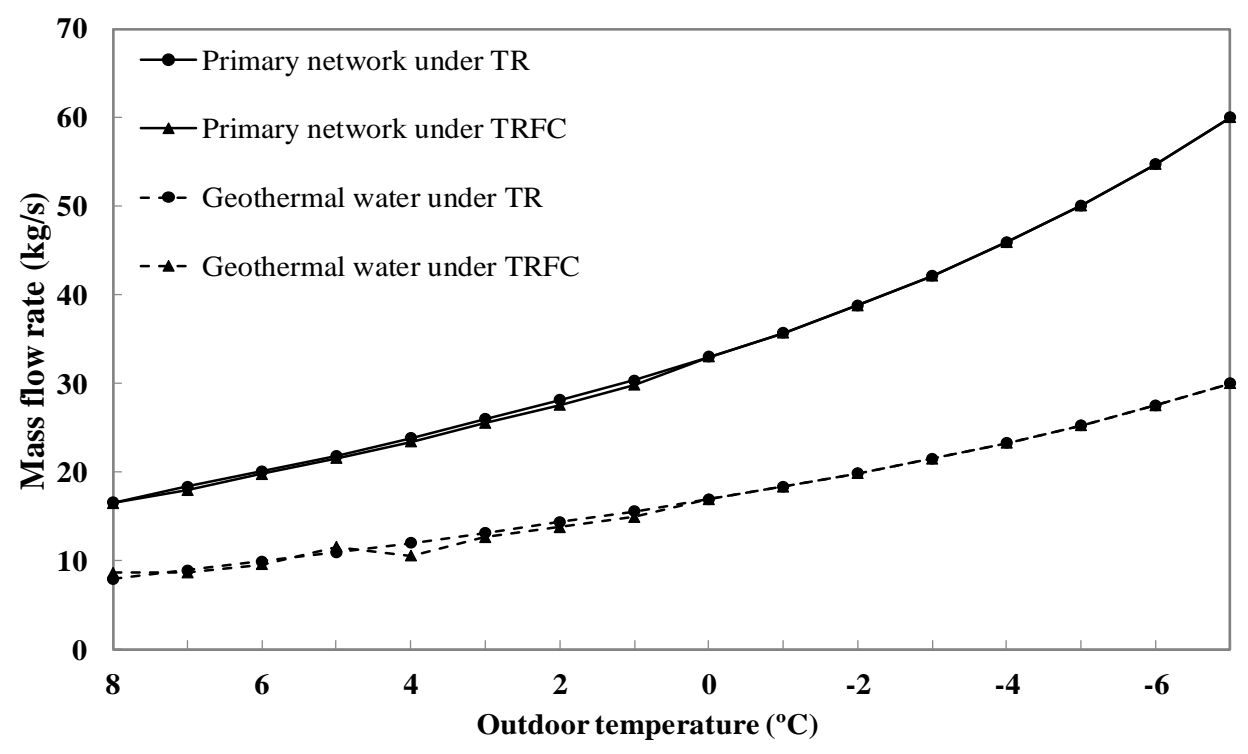

(a) Mass flow rate

Fig. 9. Comparison of TR and TRFC

Fig. 9. (b) shows that $C O P$ of the AHP under TRFC is higher than $C O P$ under TR while $t_{o} \geq 1{ }^{\circ} \mathrm{C}$. This is because of that mass flow rate and return temperature of secondary network are lower under TRFC, which increases the absorption capacity. Hence, $C O P$ of the AHP is higher. 


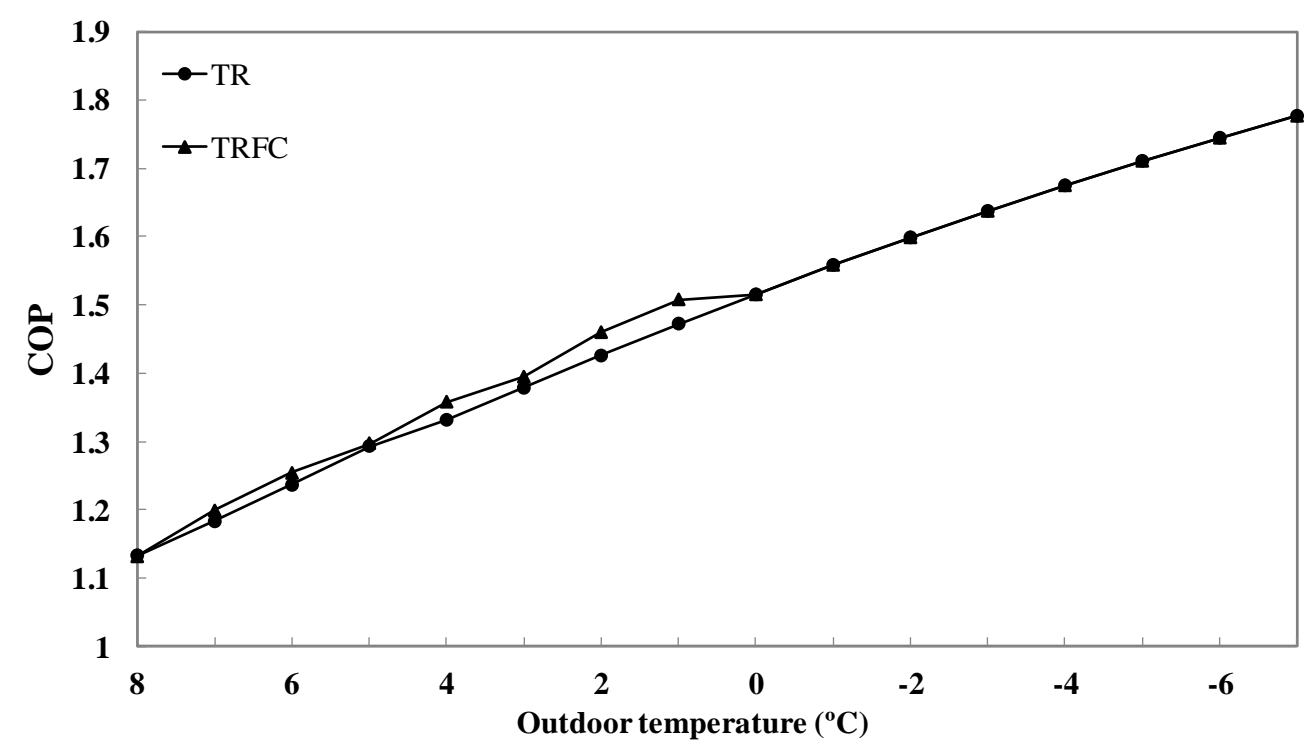

(b) $C O P$ of the AHP

Fig. 9. Comparison of TR and TRFC

In Fig. 9. (c) shows that ratio of geothermal energy under TRFC is slightly higher than the ratio under TR while $t_{o} \geq 1{ }^{\circ} \mathrm{C}$ with $\overline{m^{\prime}}=0.7$, where ratio of geothermal energy stands for ratio of heat provided by geothermal water to total heat of the secondary network. This is because of that return temperature of geothermal water under TRFC is lower and the substation exchanges more heat with geothermal water.

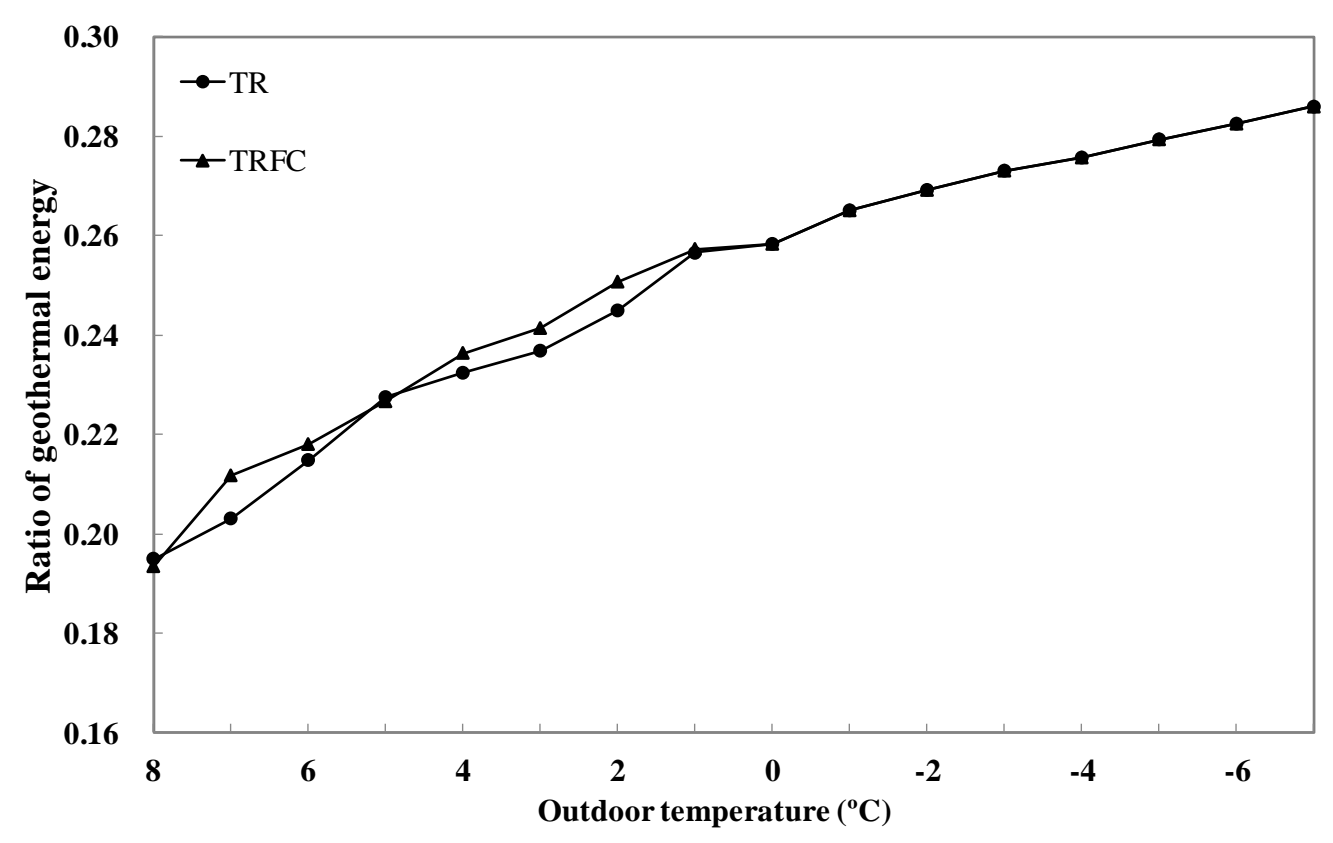


(c) Ratio of geothermal energy

Fig. 9. Comparison of TR and TRFC

In conclusion, TRFC is better than TR, which can receive a higher COP of the AHP and a higher ratio of geothermal energy in the CDHS.

\subsection{Economic analysis}

The economic analysis considered both the initial cost and annual operational cost. In this study, the annual-cost method was used to compare the CDHS and the conventional DH substation (the DH substation transferring heat from primary side to secondary side by the plate heat exchanger without integration of geothermal water assisted by the AHP) [28]. The annual-cost method converted initial cost into annual cost and added annual operational cost to get the overall annual cost. The smaller the overall annual cost, the better the economic benefit. The equation of calculating annual cost is given in Equation 36, according to [28].

$$
Z=C_{i}\left|\frac{j(1+j)^{n}}{(1+j)^{n}-1}\right|+C_{a o}
$$

where $Z$ stands for annual cost, $C_{i}$ stands for initial cost, $C_{a o}$ stands for annual operational cost, $j$ stands for annual interest rate, and $n$ stands for service life of equipment.

In this case, the initial cost and annual operational cost of CDHS and the conventional substation were obtained by the field investigation, with results listed in Table 3. The annual interest rate was $4.5 \%$ and the life of servicing equipment was assumed to be 15 years.

The initial cost of the CDHS was higher, but with higher saving on annual operational cost. As a result, the annual cost of the newly composite substation was predicted to be $660.5 \times 10^{4} ¥$ year, saved about $8.0 \%$ of the annual cost for the 
conventional substation, which costed $718.1 \times 10^{4} ¥ /$ year. This difference was mainly due to the consumption of geothermal water in the CDHS, instead of hot water from the primary network, which is much more expensive than the geothermal water. Therefore, the CDHS is more economical.

\section{Table 3}

Schedule of annual cost

\begin{tabular}{cccc}
\hline & & CDHS & Conventional DH substation \\
\hline & Geothermal well & 840 & - \\
& AHP & 200 & - \\
Initial cost & Pump & 28 & 13.5 \\
$\left(10^{4} ¥\right)$ & PHE & 5.0 & 4.3 \\
& Primary network & 644.6 & 900 \\
& Construction & 60 & 270 \\
& Mounting & 40 & 180 \\
& Total & 1817.6 & 1367.8 \\
\hline \multirow{2}{*}{ Annual operational cost } & Primary network & 380.9 & 512.0 \\
$\left(10^{4} ¥ /\right.$ year $)$ & Geothermal water & 11.3 & - \\
& Llectric & 87.5 & 60.1 \\
& Labor & 9.6 & 9.6 \\
& Maintaining & 2.0 & 590.7 \\
\hline Annual cost $\left(10^{4} ¥ /\right.$ year $)$ & Total & 660.5 & 718.1 \\
\hline
\end{tabular}

\subsection{Energy saving and reduction in pollutant emissions}

Through the study on the CDHS, under the design condition, the heating capacity directly from geothermal water and AHP is $7.9 \mathrm{MW}$, accounting for $43.9 \%$ of the total thermal load of the substation. In a heating season, there would be $31015.3 \mathrm{GJ}$ of heat saved by geothermal water and AHP, equivalent to a save of $1058.5 \mathrm{t}$ standard coal.

Comparing to the conventional DH substation, saving 31015.3 GJ means saving 
$25.6 \%$ of the primary network heat for a heating season, equal to a reduction of $25.6 \%$ of pollutant emissions. Saving $1 \mathrm{t}$ standard coal can reduce pollutant emissions of 2.62 t $\mathrm{CO}_{2}, 0.011 \mathrm{t}$ dust, $1.4 \mathrm{~kg} \mathrm{CO}, 8.5 \mathrm{~kg} \mathrm{SO}_{2}, 0.5 \mathrm{~kg} \mathrm{H} 2 \mathrm{~S}, 7.4 \mathrm{~kg} \mathrm{NO}_{\mathrm{x}}$ [34]. Therefore, according to the calculation in this study, a summary of saved pollutant emissions can be found in Table 4 .

\section{Table 4}

Reduction in pollutant emissions

\begin{tabular}{ccccccc}
\hline Standard coal & & \multicolumn{5}{c}{ Reduced pollutant emissions } \\
$(\mathrm{t})$ & $\mathrm{CO}_{2}(\mathrm{t})$ & Dust $(\mathrm{t})$ & $\mathrm{CO}(\mathrm{kg})$ & $\mathrm{SO}_{2}(\mathrm{~kg})$ & $\mathrm{H}_{2} \mathrm{~S}(\mathrm{~kg})$ & $\mathrm{NO}_{\mathrm{x}}(\mathrm{kg})$ \\
\hline 1058.5 & 2773.3 & 11.6 & 1481.9 & 8997.3 & 529.3 & 7832.9 \\
\hline
\end{tabular}

\section{Conclusions}

The utilization of renewable energy is a major development direction for district heating systems. To integrate low-temperature renewable heat into current district heating network, a Composite District Heating Substation (CDHS) with integrated geothermal water into the secondary network using Absorption Heat Pump (AHP) was proposed. The CDHS can integrate low grade geothermal water into exiting DH systems without decreasing the supply temperature of the primary network, which can avoid network reconstruction of enlarging the pipe size for lowering the supply temperature. Meanwhile, it can extract geothermal energy more deeply than the traditional geothermal system by gradient utilization. The CDHS is a convenient and efficient technique to achieve the integration of low-grade geothermal water into district heating system. Based on thermodynamic simulation and analysis, the following important conclusions would be obtained: 
1) A mathematical model of the AHP was built according to the laws of energy conservation and mass conservation. Coupling with the mathematical model of the Plate Heat Exchanger (PHE), a model was developed for the CDHS.

2) Based on thermodynamic simulation of the AHP in MATLAB, operational rules were pointed out. Raising temperature of geothermal water at the evaporator inlet, raising mass flow rate of the geothermal water, raising mass flow rate of the primary network, or lowering return temperature of the secondary network could all improve the AHP's heating capacity.

3) By simulating the CDHS under temperature regulation and under temperature regulation with flow changing in stages in MATLAB, operational curves of both the primary network and the geothermal water were obtained. By comparison, using temperature regulation with flow changing in stages in the secondary network could lead to a higher $C O P$ of the AHP and a higher ratio of geothermal energy used in the substation.

4) The CDHS is more economical and more environmental than conventional DH substation, which have no integrated renewable heat. According to results from the case study, the CDHS could save $8.0 \%$ annual cost and reduce $25.6 \%$ pollutant emissions for a heating season.

\section{Acknowledgements}

This work was supported by the State Oceanic Administration of China (Grant No. cxsf-43); and the National Natural Science Foundation of China (No. 51106110).

\section{References}

[1] O. Gudmundsson, J. E. Thorsen, and M. Brand, "The role of district heating in coupling of the 
future renewable energy," presented at the 16th International Symposium on District Heating and Cooling, Hamburg, Germany, 2018.

[2] J. Hou, M. Cao, and P. Liu, "Development and utilization of geothermal energy in China: Current practices and future strategies," Renewable Energy, vol. 125, pp. 401-412, 2018.

[3] J. Jiang, "China's Energy Policy 2012," ed. PRC, Beijing, China: Information Office of the State Council, 2012.

[4] H. Li and N. Nord, "Transition to the 4th generation district heating-possibilities, bottlenecks, and challenges," presented at the 16th International Symposium on District Heating and Cooling, Hamburg, Germany, 2018.

[5] H. Lund et al., "4th Generation District Heating (4GDH)," Energy, vol. 68, pp. 1-11, 2014.

[6] H. Lund et al., "The status of 4th generation district heating: Research and results," Energy, vol. 164, pp. 147-159, 2018.

[7] H. Lund, N. Duic, P. A. Østergaard, and B. V. Mathiesen, "Future district heating systems and technologies: On the role of smart energy systems and 4th generation district heating," Energy, vol. 165, pp. 614-619, 2018.

[8] J. Ziemele, E. Cilinskis, and D. Blumberga, "Pathway and restriction in district heating systems development towards 4th generation district heating," Energy, vol. 152, pp. 108-118, 2018.

[9] J. Ziemele, A. Gravelsins, A. Blumberga, and D. Blumberga, "Combining energy efficiency at source and at consumer to reach 4th generation district heating: Economic and system dynamics analysis," Energy, vol. 137, pp. 595-606, 2017.

[10] J. Ziemele, A. Gravelsins, A. Blumberga, G. Vigants, and D. Blumberga, "System dynamics 
model analysis of pathway to 4th generation district heating in Latvia," Energy, vol. 110, pp. 85-94, 2016.

[11] I. Pakere, F. Romagnoli, and D. Blumberga, "Introduction of small-scale 4th generation district heating system Methodology approach," presented at the 16th International Symposium on District Heating and Cooling, Germany, 2018.

[12] (2017). The 13th five-year plan for urban heating in Tianjin. (Chinese government document)

[13] A. Volkova, V. Mašatin, and A. Siirde, "Methodology for evaluating the transition process dynamics towards 4th generation district heating networks," Energy, vol. 150, pp. 253-261, 2018.

[14] L. Brange, J. Englund, K. Sernhed, M. Thern, and P. Lauenburg, "Bottlenecks in district heating systems and how to addres them," presented at the The 15th International Symposium on District Heating and Cooling, 2017.

[15] C. Keil, S. Plura, M. Radspieler, and C. Schweigler, "Application of customized absorption heat pumps for utilization of low-grade heat sources," Applied Thermal Engineering, vol. 28, no. 16, pp. 2070-2076, 2008.

[16] Y. Li, L. Fu, S. Zhang, Y. Jiang, and Z. Xiling, "A new type of district heating method with cogeneration based on absorption heat exchange (co-ah cycle)," Energy Conversion and Management, vol. 52, no. 2, pp. 1200-1207, 2011.

[17] Y. Li, L. Fu, S. Zhang, and X. Zhao, "A new type of district heating system based on distributed absorption heat pumps," Energy, vol. 36, no. 7, pp. 4570-4576, 2011.

[18] W. Wu, S. Ran, W. Shi, B. Wang, and $\mathrm{X}$. $\mathrm{Li}, " \mathrm{NH}_{3}-\mathrm{H}_{2} \mathrm{O}$ water source absorption heat pump 
(WSAHP) for low temperature heating: Experimental investigation on the off-design performance," Energy, vol. 115, pp. 697-710, 2016.

[19] Z. Qunli, C. Mingkai, Z. Qiuyue, and D. Hongfa, "Research on a New District Heating Method Combined with Hot Water Driven Ground Source Absorption Heat Pump," Energy Procedia, vol. 75, pp. 1242-1248, 2015.

[20] Q. Zhang, X. Zhang, D. Sun, and G. Wang, "Municipal space heating using a ground source absorption heat pump driven by an urban heating system," Geothermics, vol. 78, pp. 224-232, 2019.

[21] F. Sun, L. Fu, J. Sun, and S. Zhang, "A new waste heat district heating system with combined heat and power (CHP) based on ejector heat exchangers and absorption heat pumps," Energy, vol. 69, pp. 516-524, 2014.

[22] L. Fu, Y. Jiang, and S. Zhang, "District heating system based on Co-ah cycles in combined heating and power system," Journal of Tsinghua University, vol. 48, no. 9, pp. 1377-1380+1412, 2008.

[23] X. Zhao, L. Fu, W. Yuan, F. Li, and Q. Li, "The Potential and Approach of Flue Gas Waste Heat Utilization of Natural Gas for Space Heating," Procedia Engineering, vol. 146, pp. 494-503, 2016.

[24] C. Zhu, X. Xie, and Y. Jiang, "A multi-section vertical absorption heat exchanger for district heating systems," International Journal of Refrigeration, vol. 71, pp. 69-84, 2016.

[25] K. E. Herold, R. Radermacher, and S. A. Klein, Absorption Chillers and Heat Pumps. America: CRC Press, 1996. 
[26] A. de la Calle, L. Roca, J. Bonilla, and P. Palenzuela, "Dynamic modeling and simulation of a double-effect absorption heat pump," International Journal of Refrigeration, vol. 72, pp. 171$191,2016$.

[27] W. Zheng, J. Yang, H. Zhang, and S. You, "Simulation and optimization of steam operated double effect water-LiBr absorption heat pump," Applied Thermal Engineering, vol. 109, pp. 454-465, 2016.

[28] F. Sun, J. Zhao, L. Fu, J. Sun, and S. Zhang, "New district heating system based on natural gasfired boilers with absorption heat exchangers," Energy, vol. 138, pp. 405-418, 2017.

[29] Y. Kaita, "Thermodynamic properties of lithium bromide-water solutions at high temperatures," International Journal of Refrigeration, vol. 24, no. 5, pp. 374-390, 2001.

[30] L. A. Mcneely, "Thermodynamic properties of aqueous solutions of lithium bromide," ASHRAE Transactions, vol. 85, pp. 413-434, 1979.

[31] ASHRAE, ASHRAE handbook-1981 (fundamentals, no. 257). Atlanta: American society of Heating, refrigeration, and aircondition engineer Inc, 1981.

[32] W. Wagner, "The IAPWS Industrial Formulation 1997 for the Thermodynamic Properties of Water and Steam," Trans Asme Journal of Engineering for Gas Turbine \& Power, vol. 122, no. 1, pp. 150-184, 2000.

[33] Technical specification for radiant heating and cooling, 2012. (Chinese standard)

[34] W. Weilong, Boiler and Boiler-room Equipment, Five ed. Beijing: China Architecture \& Building Press, 2014. 